\title{
Molecular Pathology of RUNX3 in Human Carcinogenesis
}

Manish Mani Subramaniam ${ }^{\mathrm{a}}$, Jason Yongsheng Chan ${ }^{\mathrm{a}}$, Khay Guan Yeoh ${ }^{\mathrm{c}}$, Timothy Quek ${ }^{\mathrm{b}}$, Kosei Ito ${ }^{\mathrm{d} \dagger}$, Manuel Salto-Tellez ${ }^{\mathrm{a}, \mathrm{b}, \mathrm{c} \dagger}$

${ }^{a}$ Cancer Science Institute of Singapore (CSI), National University of Singapore, Singapore

${ }^{b}$ Department of Pathology, National University Health System, National University of Singapore,

Singapore

${ }^{c}$ Department of Medicine, National University Health System, and Faculty of Medicine, National University of Singapore, Singapore

${ }^{d}$ Graduate School of Biomedical Sciences, Nagasaki University,1-7-1 Sakamoto Nagasaki, 852-8588, Japan

†Address for Correspondence and reprint requests

Manuel Salto-Tellez, FRCPath

Associate Professor

Department of Pathology

National University Health System

Yong Loo Lin School of Medicine

National University of Singapore

5 Lower Kent Ridge Road

Singapore 119074

Tel: +65 6772-4704

Email:patmst@nus.edu.sg

Kosei Ito, $\mathrm{PhD}$

Assistant Professor

Graduate School of Biomedical Sciences

Nagasaki University

1-7-1 Sakamoto Nagasaki, 852-8588

Japan

Email: itok@nagasaki-u.ac.jp

Tel: +81 (0)95-819-7754

Fax: +81 (0)95-819-7633 


\section{Contents}

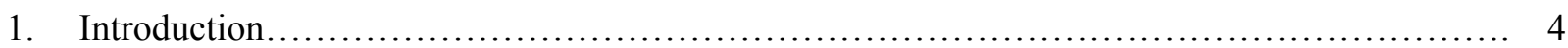

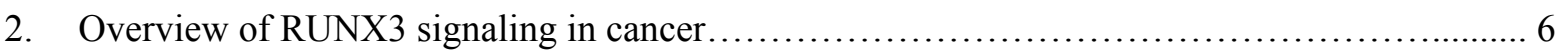

3. RUNX3 inactivation in human invasive and pre-invasive cancers...........................6

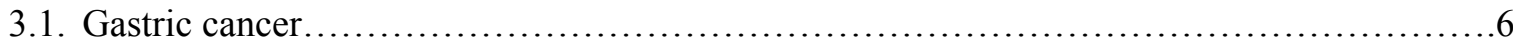

3.1.1. RUNX3 integration in the Transforming growth factor (TGF)- $\beta$ signaling pathway...6

3.1.2. Apoptosis via the death-receptor mitochondria-mediated pathway................. 8

3.1.3. RUNX3 inactivation by histone modification mechanisms....................... 8

3.1.4. RUNX3 inactivation by protein mislocalization................................ 8

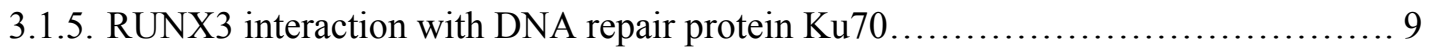

3.1.6. Role of RUNX3 in invasion, metastasis and angiogenesis of gastric cancer.......... 10

3.1.7. RUNX3, Helicobacter pylori and gastric cancer.................................... 10

3.1.8. RUNX3 inactivation in preneoplastic gastric lesions........................... 11

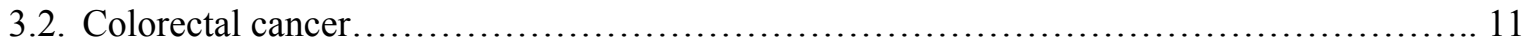

3.2.1. RUNX3 attenuates oncogenic Wnt signaling in intestinal tumorigenesis............11

3.2.2. Transducin enhancer of Split (Tle6-like/TLED) mediated the antagonism of RUNX3 in the progression of DNA mismatch repair-deficient colorectal cancers............12

3.2.3. RUNX3 inactivation in pre-invasive colorectal lesions of alternative carcinogenesis

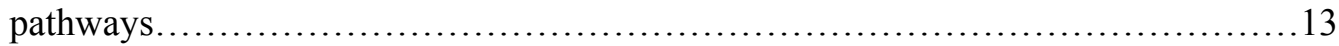

3.2.4. RUNX3 hypermethylation as a marker of the $\mathrm{CpG}$ island methylator phenotype in CRC...14

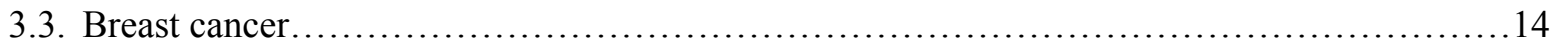

3.3.1. RUNX3 inactivation by dual mechanisms of promoter methylation and protein mislocalization.

3.3.2. Estrogen receptor signaling-mediated epigenetic RUNX3 inactivation in hormone receptor-positive breast cancers..........................................14

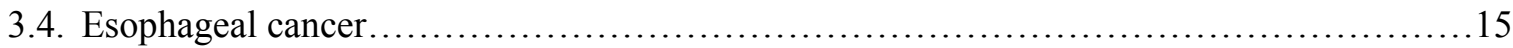

3.5. Hepatobiliary and pancreatic cancer............................................... 15

3.6. Tumors of the urinary tract and of male and female reproductive system................. 16

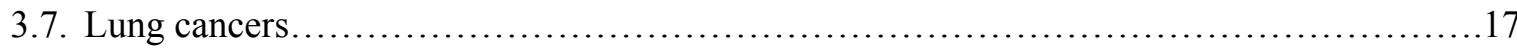

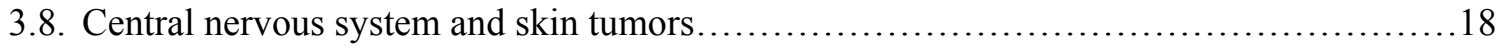

3.9. Oral, salivary gland and head and neck cancers................................... 19

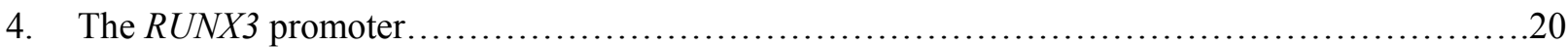

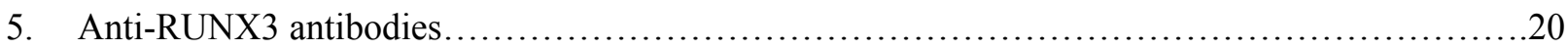

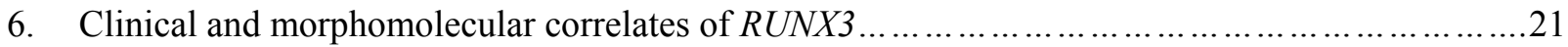

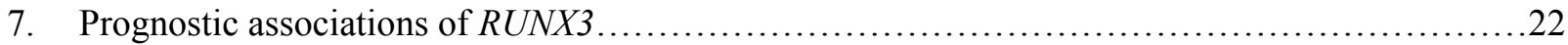

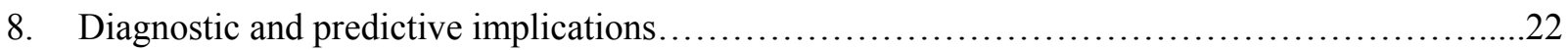

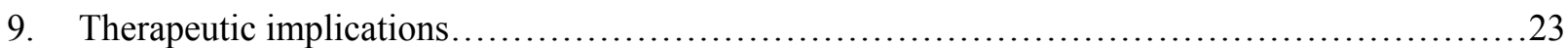

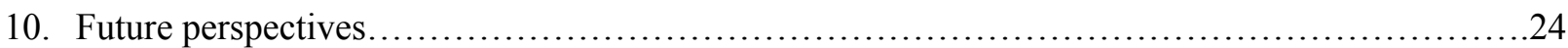

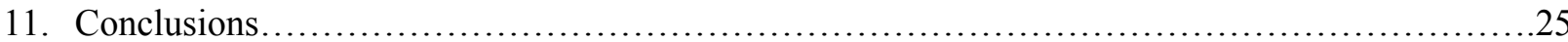

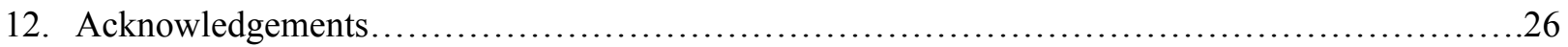

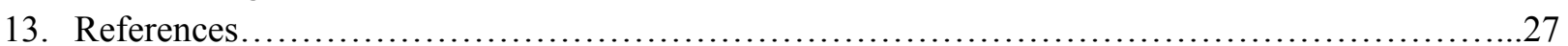




\section{Abstract}

A major goal of molecular biology is to elucidate the mechanisms underlying cancer development and progression in order to achieve early detection, better diagnosis and staging and novel preventive and therapeutic strategies. We feel that an understanding of Runt-related transcription factor 3 (RUNX3)-regulated biological pathways will directly impact our knowledge of these areas of human carcinogenesis. The RUNX3 transcription factor is a downstream effector of the transforming growth factor-beta (TGF- $\beta$ ) signaling pathway, and has a critical role in the regulation of cell proliferation and cell death by apoptosis, and in angiogenesis, cell adhesion and invasion. We previously identified $R U N X 3$ as a major gastric tumor suppressor by establishing a causal relationship between loss of function and gastric carcinogenesis. More recently, we showed that RUNX3 functions as a bona fide initiator of colonic carcinogenesis by linking the Wnt oncogenic and TGF- $\beta$ tumor suppressive pathways. Apart from gastric and colorectal cancers, a multitude of epithelial cancers exhibit inactivation of $R U N X 3$, thereby making it a putative tumor suppressor in human neoplasia. This review highlights our current understanding of the molecular mechanisms of RUNX3 inactivation in the context of cancer development and progression.

Key words: RUNX; RUNX3; cancer; epigenetics; methylation; protein expression; preneoplastic lesions; carcinogenesis; tumor suppressor gene; oncogene; apoptosis 


\section{Introduction}

Transcription factors encoded by the $R U N X$ (Runt-related transcription factor) family of genes (RUNX1, RUNX2 and RUNX3) [1] bind DNA by partnering with the cofactor, CBF $\beta /$ PEBP2 $\beta$ (core-binding factor beta subunit/polyomavirus enhancer-binding protein 2 beta subunit). The resultant complex activates and represses the transcription of principle regulators of growth, survival and differentiation pathways. $\mathrm{CBF} \beta / \mathrm{PEBP} 2 \beta$, a non-DNA binding partner that is shared by the RUNX proteins, confers high-affinity DNA binding and stability to the complex. RUNX regulates the expression of cellular genes by binding to promoters/enhancers of target genes related to cell-fate decisions, which become deranged in neoplastic cells. Runx1, which has been implicated in hematopoiesis $[2,3]$ is also a frequent target of chromosomal translocations in distinct leukemia subtypes [4]. Runx2, which is essential for osteogenesis [5,6], is altered in cleido cranial dysplasia [7]. Runx3 is necessary for gastric epithelial growth [8], neurogenesis of dorsal root ganglia [9,10] and T-cell differentiation [11]. Runx3 knockout mice exhibited gastric epithelial hyperplasia, reduced apoptosis and reduced sensitivity to TGF- $\beta 1$ [8]. About $45 \%$ to $60 \%$ of human gastric cancers displayed loss of $R U N X 3$ expression due to hemizygous deletion and promoter hypermethylation. A single loss-of-function mutation of $R U N X 3$ (R122C) in the conserved Runt domain was noted. These findings were the first demonstration of a causal link between loss of RUNX3 functions and gastric carcinogenesis [8]. Since then, $R U N X 3$ has emerged as a candidate tumor suppressor that is epigenetically inactivated in a wide spectrum of invasive [12-29] and pre-invasive $[12,15,16,21,30,31,32,73]$ epithelial and mesenchymal neoplasms [27]. A recent paradigm shift discovery by our group indicated that RUNX3 forms a ternary complex with $\beta$-catenin/TCF4 and attenuates Wnt signaling activity in initiating the development of colorectal cancer (CRC) [32]. Besides hypermethylation, inactivation of RUNX3 also occurs by mislocalization of RUNX3 protein from the nucleus to the cytoplasm [13,20,30-32]. On one hand, inactivating mutations, gene deletions, promoter hypermethylation and protein mislocalization point to a tumor-suppressor function of RUNX3 in a majority of human cancers; on the other hand, transcriptional activation by retroviral insertion clearly indicates its dominant oncogenic potential. The latter potential can be seen in Burkitt's lymphoma cell lines (group III), which 
have upregulated expression of $c-m y c$ and EBNA2, and, in turn, induce increased RUNX3 expression [33]. Additionally, RUNX3 is overexpressed in human basal cell carcinomas (BCC) [34], a skin cancer associated with deregulated Sonic hedgehog signaling as well as in head and neck squamous cell carcinomas [35] which suggests that RUNX3 has a bona fide oncogenic function. It is not clear how RUNX3 deregulation occurs via such contrasting mechanisms. In addition, how and where RUNX3 interacts with pathways that regulate growth control and differentiation are still obscure. Investigations of the factors controlling $R U N X 3$ function and its downstream effectors have begun to unravel this biological mystery. This review focuses on the existing knowledge of the role of the $R U N X 3$ gene in formation of human solid tumors/cancers and includes recent data from our group. We also discuss the clinico-pathological, prognostic and therapeutic implications of $R U N X 3$ in different cancer types, and provide some considerations for future investigations. 


\section{Overview of RUNX3 signaling in cancer}

Run $x 3^{-/-}$knock-out mice presented the following features: 1) the gastric epithelium of Runx $3^{-/-}$mice displayed hyperplasia due to increased cellular proliferation and reduced apoptosis; 2) Runx $3^{-/ 2}$ gastric epithelial cells were insensitive to the growth inhibitory effects of TGF- $\beta$; and 3 ) in nude mice, gastric epithelial cells from Runx $3^{-/-}$mice with a $p 53^{-/-}$background were tumorigenic, whereas their cellular counterparts from $\operatorname{Run} \times 3^{+/+} p 53^{-/-}$mice were not [8]. These findings indicate features of a novel tumor suppressor, RUNX3, that regulate cell proliferation and cell death by apoptosis. Recent additions to these classical functions of RUNX3 include interaction with DNA repair proteins [36], inhibition of angiogenesis [37], and involvement in cell adhesion and invasion [38]. The $1 \mathrm{p} 36$ locus that houses RUNX3 is frequently deleted in a variety of cancers, and is therefore proposed to contain crucial tumor suppressor genes [39]. The TGF- $\beta$ pathway is deranged in a majority of these cancers, and $R U N X 3$, being a downstream effector of TGF- $\beta$ [40], might provide an explanation for its broad involvement in human tumorigenesis. Table 1 summarizes the role of $R U N X 3$ inactivation in tumors of different organ systems.

\section{RUNX3 inactivation in human invasive and pre-invasive cancers}

\subsection{Gastric cancer}

The tumor suppressive functions of RUNX3 were firstly reported in gastric epithelial cells [8] and the molecular basis revealed in gastric cancer precedes the RUNX3 studies on the other human cancers. Here, we discuss the mechanisms by which $R U N X 3$ exercises its tumor suppressive activity and its interaction with other cancer-signaling molecules in the context of gastric carcinogenesis (Figure 1).

\subsubsection{RUNX3 integration in the Transforming growth factor (TGF)- $\beta$ signaling pathway}

Transforming growth factor- $\beta$ when bound to their respective cognate receptors are activated as serine kinases, which then phosphorylate signal transducers called Smads. TGF- $\beta$ activates Smad2 and 3 (R-Smads), which associate with a common Smad4 (Co-Smad) and enter the nucleus, where the 
R-Smad/Co-Smad complexes bind to transcription factors in order to regulate the transcription of target genes. RUNX3 interacts with R-Smads as well as p300, a transcriptional co-activator. Smad2/3, Smad4, p300 and RUNX3 are collectively required for the tumor suppressor activity of the TGF- $\beta$ pathway [40]. TGF- $\beta$ causes cell cycle arrest at the mid-and late-G1 phases of the cell cycle by inactivating cyclin-dependent kinases (cdks) through the induction of cdk inhibitors. However, the lineage-specific transcription factor that cooperates with Smads to induce $p 21$ expression was unknown at that time. Chi et al. (2005) [41] showed that RUNX3 inhibits gastric epithelial cell growth by inducing p21 gene expression in response to TGF- $\beta 1$. Exogenous RUNX3 expression increased endogenous p21 expression in response to TGF- $\beta 1$, suggesting the involvement of RUNX3 in the TGF- $\beta$ pathway. RUNX3 suppression decreased TGF- $\beta 1$-induced endogenous p21 expression. Together, these results indicate that the tumor suppressor activity of RUNX3 is partially linked to its ability to induce p21 expression [41]. RUNX3 binds to conserved RUNX binding elements (RBE1 and RBE2) in the Bim (the Bcl-2 interacting mediator of cell death) promoter, and physically interacts with the Forkhead transcription factor, FoxO3a/FKHRL1, an important regulator of apoptosis and the cell cycle, to activate the expression of Bim, a proapoptotic gene [42]. The gastric epithelium of Runx $3^{-/-}$mice had reduced levels of Bim expression, and of apoptosis, which was reduced to a similar extent as in $\mathrm{Bim}^{-/-}$mice. Furthermore, comparable expression of TGF- $\beta 1$ and TGF- $\beta$ receptors was noted in the wild-type and Run $x 3^{-/-}$gastric epithelium, and levels of Bim were reduced in the stomachs of $T G F-\beta^{-\alpha}$ mice, thereby confirming the role of RUNX3 in Bim upregulation in TGF- $\beta$-induced apoptosis [43]. GASDERMIN (GSDM), was found to be expressed in the gastric pit epithelial cells, but to be suppressed in gastric cancer cell lines [44]. GSDM possesses high apoptotic activity, and its expression is regulated by a transcription factor, Lim domain only 1 (LMO1), through a sequence to which RUNX3 binds in the GSDM promoter region [45]. Coexpression of GSDM with LMO1, $R U N X 3$ and type II TGF- $\beta$ receptor (TGF- $\beta R I I)$ was detected in gastric pit cells [45]. In addition, TGF- $\beta$ upregulated LMO-1 and GSDM expression in the gastric epithelial cell lines, and induced apoptosis. This confirmed that induction of apoptosis is inhibited by the suppression of $L M O-1, R U N X 3$ or GSDM expression [45].

\subsubsection{Apoptosis via the death-receptor mitochondria-mediated pathway}


In the MKN-1 gastric cancer cell line, forced RUNX3 expression in the Tet-regulated adenoviral vector induced apoptosis by death-receptor molecules. RUNX3 upregulated 17 apoptosis-related genes, including Fas-associated death domain, $(F A D D)$, TRAF6, Caspase-2, ING1, ING4, Calpain 10 and DNase 1, and downregulated 135 apoptosis-related genes, including FLICE/caspase-8 inhibitory protein (FLIP), PEA15, TXN2, HSPD1, IKK and TIAL1. Further analyses also suggested that promotion of the formation of the death-inducing signaling complex and activation of the mitochondria-mediated pathway were associated with RUNX3-induced apoptosis. These results suggest that exogenous RUNX3 expression suppresses cell proliferation by inducing apoptosis via the death-receptor mitochondria-mediated pathway in $\mathrm{MKN}-1$ cells [46].

\subsubsection{RUNX3 inactivation by histone modification mechanisms}

The expression of RUNX3 was downregulated at the transcriptional level in response to hypoxia in human gastric cancer cells. This downregulation was abolished by treatment with the histone deacetylase (HDAC) inhibitor, trichostatin A (TSA), and the cytosine methylation inhibitor, 5-aza-2-deoxycytidine (5-Aza), suggesting that an epigenetic regulatory mechanism may be involved in RUNX3 silencing by hypoxia. Increased histone H3-lysine 9 dimethylation and decreased H3 acetylation in the RUNX3 promoter was observed upon hypoxic treatment of gastric cancer cells. Hypoxia caused upregulation of G9a histone methyltransferase and HDAC1. Overexpression of G9a and HDAC1 inhibited the nuclear localization and expression of $R U N X 3$. The authors of this study proposed that hypoxia silences RUNX3 by epigenetic histone regulation during the progression of gastric cancer [47]. Moreover, overexpression of enhancer of zeste homologue 2 (EZH2) caused H3K27 trimethylation of the RUNX3 promoter, which led to repression of $R U N X 3$ expression in the absence of DNA methylation [48].

\subsubsection{RUNX3 inactivation by protein mislocalization}

Mislocalization of active nuclear RUNX3 protein to the cytoplasm was initially observed in gastric cancers [13], and followed by cancers of the breast [20,30] and liver (Quek T et al., unpublished data), and by colorectal polyps [31] and CRCs (Figure 2) [32, 106]. We noted that RUNX3 protein 
accumulated in the nucleus of SNU16 cells after 6 hours of treatment with TGF- $\beta$, suggesting that RUNX3 is translocated to the nucleus by TGF- $\beta$ stimulation [13]. In a nude mouse assay, SNU16 cells stably expressing RUNX3(1-187), a truncated form of RUNX3, induced tumors that were larger than the control tumors formed by parental cells expressing endogenous full-length RUNX3 [13]. Our results confirmed that RUNX3 was primarily confined to the cytoplasm of cells in RUNX3 (1-187)-induced tumors, whereas a substantial fraction of RUNX3 was present in the nucleus of cells in control tumors [13]. Our data suggest that cytoplasmic RUNX3 protein does not elicit tumor suppressive activity, and that it is therefore a novel mechanism of RUNX3 inactivation [13]. More recently, Kim et al (2009) [49] showed that Jun-activation domain-binding protein 1 (Jab1/CSN5) physically interacts with RUNX3 and facilitates chromosomal region maintenance 1 (CRM1)-dependent nuclear export. Subsequently, the sequestered RUNX3 protein in the cytoplasm is degraded through a proteosome-mediated pathway with the help of COP9 signalosome (CSN)-associated kinases. In contrast, Pim-1 phosphorylates four Ser/Thr residues within the Runt domain and thereby stabilizes the RUNX3 protein. In addition, it also alters the cellular localization of RUNX3 from the nucleus to the cytoplasm [50]. Pim-1 conferred stability to RUNX3, and Pim-1-induced cytoplasmic translocation of the RUNX3 protein could result in depletion of nuclear factors associated with RUNX3, thereby turning it into an oncogene [50]. Thus, it is intriguing that the function of RUNX3 as a cell fate regulator depends on its cellular localization.

\subsubsection{RUNX3 interaction with DNA repair protein $K u 70$}

Using a proteomic approach, Ku70, a member of the DNA repair protein complex, was found to be bound to the transactivation domain of RUNX3, and was shown to interfere with RUNX3 transcription [36]. This was evident when RUNX3 markedly activated the transcription of p21, the target gene of Runx3, in Ku70 knockdown cells [36]. RUNX3 and Ku70 might regulate the cell cycle and balance cell growth by controlling p21 expression. Collectively, these data suggest a possible link between a tumor suppressor function and DNA repair, although further precise studies are needed to understand the significance of this interaction [36]. 


\subsubsection{Role of RUNX3 in invasion, metastasis and angiogenesis of gastric cancer}

RUNX3 transfection in gastric cancer cells resulted in TGF- $\beta$-induced anti-proliferative and apoptotic effects. In addition, inhibition of peritoneal metastases of gastric cancer in animals was also noted [38]. Microarray analysis of RUNX3 transfectants revealed upregulation or downregulation of genes involved in peritoneal metastasis related to cell adhesion (Sialyltransferase I, Annexins 5/7, galectin 4), signal transduction (vav3, MET, S100A11, MAPKK), apoptosis (caspase9) and immune responses (CD55 and TLR1O). Thus, RUNX3 silencing affects the expression of critical metastasis-related genes that promote peritoneal metastasis of gastric cancers [38]. Furthermore, loss of RUNX3 expression correlated directly with increased vascular endothelial growth factor $(V E G F)$ expression and tumor angiogenesis. Restoration of RUNX3 expression suppressed the angiogenic potential of gastric cancer cells, and correlated with downregulated $V E G F$ expression via promoter repression in vitro, and attenuation of tumorigenicity and abrogation of metastasis in animal models [37]. Thus, RUNX3 negatively regulates the angiogenesis, growth and metastasis of gastric cancer.

\subsection{7. $R U N X 3$, Helicobacter pylori and gastric cancer}

Helicobacter pylori (H. pylori)-induced release of cytokines, reactive oxygen species and nitric oxide may hypermethylate $\mathrm{CpG}$ islands by activating DNA methyltransferase, as in the case of $E$-cadherin [51]. H. pylori-infected individuals exhibited increased promoter methylation, and were associated with an increased risk of gastric cancer compared with H. pylori-negative individuals [52]. Nakajima et al. (2009) proposed the existence of a methylation fingerprint of $H$. pylori in infected gastric mucosae. [53]. However, so far, only a solitary report exists that links methylation of the $R U N X 3$ promoter with $H$. pylori infection in gastric cancers [54]. Persistent H. pylori infection in the middle and lower portions of the stomach has been shown to induce $R U N X 3$ hypermethylation in the epithelial cells, which results in intestinal metaplasia and cancer [54]. 


\subsubsection{RUNX3 inactivation in preneoplastic gastric lesions}

The non-neoplastic mucosa of the stomach, unlike that of other organs, exhibits frequent age-related $R U N X 3$ methylation that is commonly seen in people above the age of 77 years [55]. Besides age-related methylation, increased field effect-related $R U N X 3$ methylation was also observed in the residual gastric mucosa resulting from resection of a remnant stomach for gastric cancers, but not in that of an intact stomach. Thus, an evaluation of $R U N X 3$ methylation status in normal gastric mucosa may provide an estimate of the risk for gastric carcinogenesis [56]. Li et al. (2002) showed that expression of RUNX3 was reduced in some intestinal metaplasias [8], and gastric epithelial cells of $\operatorname{Run} x 3^{-/} p 53^{-/-}$mice also differentiated into intestinal-type cells $[57,58]$. Other precursor gastric lesions, such as chronic gastritis [15] and gastric adenomas [15], also showed $R U N X 3$ hypermethylation, indicating a role for $R U N X 3$ in gastric cancer progression.

\subsection{Colorectal cancer}

\subsubsection{RUNX3 attenuates oncogenic Wnt signaling in intestinal tumorigenesis}

Inactivating mutations of the $A P C$ gene, which encodes a key regulator of the canonical Wnt pathway that destabilizes $\beta$-catenin, is a well-characterized mechanism of colonic carcinogenesis [59]. A recent discovery by our group provided evidence of cross-talk between these two pathways in intestinal tumorigenesis [32]. The intestinal epithelia of $R u n \times 3^{-/-}$mice showed increased proliferation and increased $\beta$-catenin/Tcf4 activity, as evidenced by the upregulation of target genes (CD44, cyclin D1, c-Myc, Axin2/conductin, and EphB2) activated by $\beta$-catenin. In HCT116 cells, endogenous $\beta$-catenin, TCF4 and RUNX3 coimmunoprecipitated, forming a ternary complex (Figure 3A). RUNX3 inhibited the DNA binding of $\beta$-catenin/TCF4 in vivo and vitro, and prevented transactivation of $\beta$-catenin/TCF4. Knockdown of endogenous RUNX3 in RUNX3-positive cells enhanced the binding of $\beta$-catenin/TCF4 to cyclin D1 and $c-M y c$ promoters, whereas induction of exogenous RUNX3 in RUNX3-negative cells downregulated the binding of $\beta$-catenin/TCF4 to cyclin D1 and $c$-Myc promoters. These data confirmed that RUNX3 attenuates oncogenic Wnt activity by interacting with $\beta$-catenin/TCF4. The $R u n x 3^{+/-}$and $A p c^{\mathrm{Min} /+} \mathrm{BALB} / \mathrm{c}$ mice developed adenomas in the small intestine, but not in the large intestine. Adenomatous polyps of 
$A p c^{\mathrm{Min} /+}$ showed loss of heterozygosity (LOH) of $A P C$, and nuclear $\beta$-catenin accumulation, while $R u n x 3^{+/-}$ mice revealed downregulated Runx3 expression due to hypermethylation of the Runx3 promoter. In contrast, $\operatorname{Run} \times 3^{+/} A p c^{\mathrm{Min} /+}$ double compound mice exhibited adenomatous polyps in the small and large intestines and adenocarcinomas in the small intestine at 65 weeks. The frequency of tumor formation, and the number and size of tumors were enhanced in the $R u n \times 3^{+/-} A p c^{\mathrm{Min} /+}$ mice compared to $R u n \times 3^{+/-}$and $A p c^{\mathrm{Min} /+}$ mice. Immunohistochemical analysis showed that the small adenomas of the $R u n \times 3^{+/-} A p c^{\mathrm{Min} /+}$ mice had either downregulated $R U N X 3$ expression or nuclear $\beta$-catenin accumulation, but never both, indicating that biallelic inactivation of either Runx3 or Apc is sufficient for adenoma induction. However, large adenomas and adenocarcinomas display aberrant nuclear/cytoplasmic $\beta$-catenin accumulation in the Run $x 3^{+/}$background, which suggests that alteration of both genes causes strong Wnt activation. Consistent with these observations in the mouse adenomas, human adenomatous polyps frequently revealed either nuclear/cytoplasmic $\beta$-catenin accumulation with nuclear RUNX3 expression or reduced RUNX3 expression without $\beta$-catenin accumulation. However, in human colorectal adenocarcinomas, both RUNX3 downregulation and nuclear/cytoplasmic $\beta$-catenin accumulation occur in a significant fraction of cases, suggesting that both RUNX3 inactivation and $\beta$-catenin activation are necessary for the progression of adenomas to adenocarcinomas (Figure 3B). These results suggest that RUNX3 negatively controls the strength of Wnt signaling by stimulating physiological Wnt ligands or by APC inactivation or $\beta$-catenin activation, through RUNX3/ $\beta$-catenin/TCFs ternary complex formation. We propose that RUNX3 functions as a 'brake' in oncogenic Wnt signaling, and that RUNX3 inactivation is an initiator of adenoma formation, as is the alteration of $A P C$ in humans and mice [32].

\subsubsection{Transducin enhancer of Split (Tle6-like/TLED) mediated the antagonism of RUNX3 in the} progression of DNA mismatch repair-deficient colorectal cancers

Chen and co-workers (2008) [60] observed increased tumor multiplicity and increased frameshift and base-substitution mutations of $A p c$ in $M l h 3$-, Pms2- and Apc- deficient mouse models. Tumor progression in these mice was also associated with amplification of the Transducin enhancer of Split gene (Tle6-like) amplicon on chromosome 12F2. Increased expression of Tle6-like or the human alternative spliced isoform (TLED) was observed in a subset of human CRCs with positive RUNX3 expression. 
Expression of Tle6-like or the TLE6D splice isoform in colon cancer cells increased cell proliferation, colony-formation, cell migration and xenograft tumorgenicity. Coimmunoprecipitation assays demonstrated that TLED interacted with RUNX3, which resulted in the inhibition of RUNX3 target transactivation, thereby providing a selective growth advantage for cell proliferation and migration. However, the functional significance of this interaction in CRC progression is still unclear.

\subsubsection{RUNX3 inactivation in pre-invasive colorectal lesions of alternative carcinogenesis} pathways

We examined RUNX3 inactivation in (A) the traditional adenoma-carcinoma sequence and (B) the serrated colorectal pathway [31]. We also assessed it in (C) the familial adenomatous polyps (FAP) (Figure 4). Pre-invasive lesions of the serrated colorectal pathway (B), such as hyperplastic polyps (15 of $19,79 \%$ ) and traditional serrated adenomas ( 8 of 14, 57\%), displayed significant downregulation of RUNX3 expression, compared to the normal colon samples ( 2 of 12, 16\%) and sporadic traditional adenomas, pre-invasive lesions of (A), (3 of 17, 18\%) $(p<0.05)$. In FAP (C) specimens $(\mathrm{n}=19)$, aberrant crypt foci ( 78 of 91, 86\%), small adenomas ( 25 of 40, 62\%), and large adenomas ( 6 of 13, 46\%) exhibited more frequent RUNX3 downregulation than did their adjacent normal mucosa ( 0 of 19, $0 \%$ ) (all $p<0.05)$. In all colonic carcinogenesis models (A-C), $R U N X 3$ hypermethylation was more frequent in colorectal polyps $(64$ of $87,74 \%)$ than in the normal colon $(2$ of $12,16 \%)(p=0.001)$. The $R U N X 3$ promoter had significantly more methylation in pre-invasive lesions of (B) (hyperplastic polyps, 17 of 19, 89\%; and traditional serrated adenomas, 12 of 14, 86\%) than in pre-invasive lesions of (A) (sporadic traditional adenomas, 7 of $17,44 \%)(p=0.004)$, consistent with the frequent occurrence of DNA methylation in the polyps of the serrated neoplasia pathway [61]. However, the end-point histological lesions in (B), serrated adenocarcinomas, were not included in this study, and the $R U N X 3$ promoter status in the late stages of serrated polyp pathway remains unknown. The $R U N X 3$ promoter was hypermethylated in (C) FAP polyps (28 of 38, 74\%). Hypermethylation correlated with RUNX3 silencing in (A and B) sporadic (27 of 36, 75\%; $p=0.022)$ and (C) FAP ( 21 of $28,75 \% ; p=0.021)$ polyps. 


\subsubsection{RUNX3 hypermethylation as a marker of the $C p G$ island methylator phenotype in $C R C$}

Approximately $20 \%$ of primary CRCs show promoter hypermethylation associated with transcriptional silencing $[14,32,107,108]$. This cancer-specific epigenetic event has led to the inclusion of $R U N X 3$ in a panel of five markers proposed to define a distinct subset of CRCs, termed the CpG island methylator phenotype (CIMP) [62]. This CIMP trait is tightly linked to microsatellite instability (MSI) and a high frequency of BRAF mutations in CRCs [62]. RUNX3 hypermethylation as a part of CIMP-positive CRCs has been correlated with a variety of molecular, clinical, histopathological and epidemiological features. A discussion of these features is beyond the scope of this review.

\subsection{Breast cancers}

\subsubsection{RUNX3 inactivation by dual mechanisms of promoter methylation and protein} mislocalization

Kim et al (2004) [15] and Suzuki et al (2005) [27] provided the first evidence that RUNX3 hypermethylation is a characteristic of breast cancers. Besides $R U N X 3$ hypermethylation, we demonstrated that protein mislocalization also contributes to RUNX3 inactivation (Figure 2). Using an in-house generated anti-RUNX3 monoclonal antibody, we demonstrated loss of RUNX3 function in the form of mislocalization of the RUNX3 protein [20]. The normal breast acini had unmethylated RUNX3 and showed strong nuclear RUNX3 expression, in contrast with the RUNX3-methylated cancer tissues. Extending our study to precursor breast lesions, we detected frequent instances of $R U N X 3$ hypermethylation $(75 \%, \mathrm{n}=40)$ and loss of $R U N X 3$ expression (88\%, $\mathrm{n}=40$ ) in ductal in situ carcinomas (DCIS) (Figure 4) [30]. In addition, copy number reductions [63] and $\mathrm{LOH}[64]$ in the $R U N X 3$ region have also been reported to contribute to the loss of $R U N X 3$ in breast cancers.

\subsubsection{Estrogen receptor signaling-mediated epigenetic RUNX3 inactivation in hormone} receptor-positive breast cancers

Estrogen imprinting refers to acquisition of increased risk of breast cancer in adult life owing to early developmental exposure to endocrine disruptors. Cheng et al. (2008) [65] used mammospheres 
containing enriched breast progenitor stem cells as an exposure system to simulate this imprinting phenomenon in vitro. The estrogen-exposed colonies formed out of these breast progenitors expressed nuclear estrogen receptor $(\mathrm{ER} \alpha)$, whereas non-exposed colonies did not. Methylation microarray screening revealed increased hypermethylation, accounting for $0.5 \%$ (120) of $\mathrm{CpG}$ loci, including those found in the RUNX3 promoter, in epithelial cells derived from estrogen-exposed progenitors, compared to that in the non-estrogen-exposed control cells. Estrogen induced-RUNX3 hypermethylation was seen in both primary tumors and in the adjacent normal breast tissue, indicating that hypermethylation of $R U N X 3$ is an early event in breast carcinogenesis. $R U N X 3$ mRNA expression is negatively correlated with ER $\alpha$ expression in invasive ductal cancers. These data provide empirical evidence of a link between estrogen injury of breast stem/progenitor cells and carcinogenesis through estrogen-induced epigenetic changes.

\subsection{Esophageal cancers}

Introduction of RUNX3 in SEG1, a Barrett's esophagus-derived cell line unresponsive to TGF- $\beta$, led to a drastic increase in TGF- $\beta$ antiproliferative activity and apoptotic induction, while transfection of RUNX3 in the absence of TGF- $\beta$ had no effect on the proliferation and apoptosis of SEG1 cells. These results were the first to suggest that RUNX3 is essential for the antiproliferative and apoptotic effects of TGF- $\beta$ in SEG1 cells [67]. Subsequently, frequent $R U N X 3$ inactivation by promoter hypermethylation was noted in esophageal squamous cell carcinomas (ESCC) [68-70], adenocarcinomas (EAC) [12, 71], and Barrett's metaplasia [12] and dysplasia [12]. RUNX3 induces Bim expression and enhances sensitivity to radiation and TGF- $\beta$-induced apoptosis in ESCC cells, thereby acting as an important determinant of radiosensitivity [69]. RUNX3 promotes radiosensitivity, while its inactivation promotes radioresistance [69].

\subsection{Hepatobiliary and pancreatic cancers}

In hepatocellular carcinoma (HCC), promoter hypermethylation and $\mathrm{LOH}$ of $R U N X 3$ were frequently detected [72-77]. However, the frequency of LOH at RUNX3 $(37.8 \%, \mathrm{n}=37$ [72] and 34.6\%, $\mathrm{n}=26$ [77], respectively) was less than the frequency of methylation $(48.4 \%, \mathrm{n}=62[77]$ and $75.6 \%, \mathrm{n}=41$ [72], respectively), and the majority of methylated cases exhibited $\mathrm{LOH}$, suggesting that $\mathrm{LOH}$ at $R U N X 3$ 
and hypermethylation of the $R U N X 3$ promoter are common mechanisms of $R U N X 3$ inactivation in hepatocarcinogenesis [72]. In our experience (T. Quek, unpublished data), normal liver tissues displayed nuclear $R U N X 3$ expression in more than $80 \%$ of the hepatocytes. In contrast, 21 of $34(62 \%)$ of HCCs displayed inactivation of $R U N X 3$, of which 6 (29\%) showed complete negativity, while 15 (71\%) revealed cytoplasmic mislocalization of the RUNX3 protein, in both methylated and non-methylated samples (Figure 2). RUNX3 hypermethylation was observed in 3 of 6 (50\%) RUNX3-negative cases, whereas none of the matched non-neoplastic liver samples exhibited methylation. Additionally, in a recent study, $R U N X 3$ methylation as a single molecular marker was demonstrated to be sensitive and specific in detecting $45 \%$ and $90 \%(n=20)$ of well differentiated HCCs, $21 \%$ and $89 \%(n=28)$ of small HCCs (less than $3 \mathrm{~cm})$ and $29 \%$ and $91 \%(\mathrm{n}=35)$ of early HCCs (TNM stages I and II) [76]. $R U N X 3$ hypermethylation is also a marker of clonality in multicentric HCCs, thus distinguishing multicentric HCCs from a true clinical relapse [74]. RUNX3 hypermethylation is also seen in chronic hepatitis and non-cancerous liver tissues of both HCV-positive and HCV-negative HCC cases, but is absent in normal liver tissues [75].

Loss of RUNX3 expression due to promoter hypermethylation was seen in 7 of $10(70 \%)$ bile duct and 9 of $12(75 \%)$ pancreatic cancer cell lines [18]. About 56.8\% $(n=37)$ of primary biliary tract cancers, including cancer of the bile duct, gallbladder, and duodenal ampulla, also showed $R U N X 3$ hypermethylation [17]. Tumor-specific methylation of $R U N X 3$ was also noted in pure primary gallbladder carcinomas [16]. RUNX3 expression was restricted to islets in the normal pancreas. Increased RUNX3 expression was observed in chronic pancreatitis, while loss of expression was noted in primary and metastatic cancers [78]. These results portray a possible tumor suppressor role for $R U N X 3$ in biliary tract and in pancreatic cancers.

\subsection{Tumors of the urinary tract and of male and female reproductive system}

RUNX3 hypermethylation was seen in 73\% $(\mathrm{n}=124)$ of primary bladder cancers and $86 \%(\mathrm{n}=7)$ of tumor cell lines [80]. Normal bladder tissues did not show RUNX3 hypermethylation, and RUNX3 methylation was not found to be age-related. Two patients with point mutations of $R U N X 3$ also contained a wild-type $R U N X 3$ allele, indicating that haploinsufficiency of $R U N X 3$ increases the risk of bladder cancer 
[80]. The in situ hypermethylation of RUNX3 in preneoplastic lesions, such as cystitis cystica and multifocal carcinoma, indicates that $R U N X 3$ hypermethylation occurs early in bladder tumorigenesis, and accumulates irreversibly in bladder stem cells, which may eventually progress to cancer [82]. In prostate cancers, $R U N X 3$ hypermethylation was detected in $32.4 \%(\mathrm{n}=37)$ of prostate cancers and $14.3 \%(\mathrm{n}=14)$ of prostatic intraepithelial neoplasia (PIN), and was absent in normal/benign prostatic tissue [21], indicating the involvement of $R U N X 3$ in multistep prostatic carcinogenesis.

Ovarian granulosa cell tumors showed methylation of FHIT $(28 \%, \mathrm{n}=25), F N A C F(24 \%, \mathrm{n}=25)$, Cyclin D2 $(12 \%, \mathrm{n}=25)$, BRCA2 $(4 \%, \mathrm{n}=25)$ and $R U N X 3(56 \%, \mathrm{n}=25)$ [22]. Promoter hypermethylation correlated with gene silencing in tumor cell lines [22]. In contrast, the overexpression of RUNX3 in epithelial serous ovarian carcinomas, compared to expression in normal ovarian epithelium, suggested a possible oncogenic potential for RUNX3 [23]. Although RUNX3 mRNA levels were higher in these tumors than in normal ovarian epithelium, immunohistochemical analysis revealed that RUNX3 was expressed in the cytoplasm and not in the nucleus. As mislocalized RUNX3 is considered to be an inactive protein [13], the oncogenic role of RUNX3 in these tumors is not clear [23]. In infantile testicular yolk sac tumors, deletion of the distal $1 \mathrm{p}$ spanning $1 \mathrm{p} 36$ is relatively frequent, differentiating these types of tumors from their adult counterparts. Further investigation confirmed that both $R U N X 3$ hypermethylation and LOH at $1 \mathrm{p} 36.1$ were very frequent in infantile testicular yolk sac tumors [24]. However, normal testis and testicular intratubular germ cell neoplasias, which are precursors of germ cell tumors, did not have hypermethylated $R U N X 3$ [85].

\subsection{Lung cancers}

Among the human non-small cell lung carcinoma (NSCLC) samples, p16 methylation was more frequent in squamous cell carcinomas than in adenocarcinomas. In contrast, $A P C[26]$ and $R U N X 3[86,87]$ were frequently methylated in cases of adenocarcinoma. Thus, differential gene methylation contributes to the development of different lung cancer phenotypes. In addition, $R U N X 3$, one of the genes identified in a panel of Wnt antagonists, such as $A P C, D K K 1, D K K 3, L K B 1, S F R P 1,2,4,5$ and WIFl was methylated in $28.3 \%(n=46)$ of normal lung tissues, and in $28.1 \%$ of low $(n=32)$ and $70.8 \%(n=24)$ of high grade atypical adenomatous hyperplasias, which are supposedly precursors of lung adenocarcinoma [88]. These findings 
indicate a role for $R U N X 3$ inactivation in primary lung cancer development and progression, especially of glandular neoplasia of lung.

\subsection{Central nervous system and Skin tumors}

Glioblastomas have a grave prognosis, and are the most aggressive, most common, and least treatable form of malignant gliomas. They are known to exhibit aberrant DNA methylation [92]. A solitary report, which involved the pharmaceutical unmasking of epigenetic alterations with 5-aza-dC, coupled with a cRNA microarray analysis, in tumor cell cultures, showed that both RUNX3 and Testin harbored frequent tumor-specific methylation in primary glioblastomas [28]. However, the functional importance of methylation of $R U N X 3$ in glioblastomas remains unclear.

Deregulation of downstream molecules of sonic hedgehog signaling (Shh) [93] and Wnt signaling [94] pathways has been implicated in BCCs. In the context of these findings, we tested the expression of RUNX3 and $\beta$-catenin, the downstream effectors of the TGF- $\beta$ /BMP (bone morphogenic protein) and Wnt pathways, respectively, in BCCs. We found that almost all $(100 \%, \mathrm{n}=75)$ BCCs overexpressed RUNX3 in the nucleus. Nuclear $\beta$-catenin accumulation was seen in $41 \%(n=75)$ of BCCs in contrast to the basal cells of normal skin, which displayed mainly membranous expression and lacked nuclear reaction to $\beta$-catenin. The latter data suggested aberrant Wnt activation in a subset of BCCs [34]. Taken together, our results indicate an oncogenic role for $R U N X 3$ in BCCs, and also suggest a possible oncogenic interaction between the TGF- $\beta$ /BMP pathway and Wnt signaling in promoting tumorigenesis. On the other hand, RUNX3 mRNA expression was downregulated in majority of primary $(100 \%, \mathrm{n}=82)$ and metastatic $(100 \%, \mathrm{n}=41)$ cutaneous melanomas compared to normal skin suggesting a tumor suppressor role of RUNX3 in melanoma progression [91]. However, promoter hypermethylation contributed to loss of RUNX3 expression in a very less proportion of primary $(4 \%, n=52)$ and metastatic $(17 \%, n=30)$ cutaneous melanomas [91]. Instead, a microRNA (miR-532-5p) identified as a target of RUNX3 mRNA sequences was significantly up-regulated in melanoma lines and metastatic melanoma tumors relative to normal melanocytes and primary melanomas, respectively. On analyzing the relation between RUNX3 and miR-532-5p, it was noted that inhibition of miR-532-5p up-regulated both RUNX3 
mRNA and protein expression [91]. This data suggest that the expression of tumor suppressor RUNX3 in cutaneous melanomas is regulated by miR-532-5p [91].

\subsection{Oral, salivary gland and head and neck cancers}

RUNX3 was weakly expressed in normal oral epithelia, but strongly expressed in dysplastic oral squamous epithelia, which develop into oral squamous cell carcinoma [95]. RUNX3 expression was noted in the cytoplasm of the upper and middle layers of normal and dysplastic squamous mucosa, and in the cancer cells around the cancer pearls of invasive squamous cell carcinomas. RUNX3 expression was associated with well-differentiated squamous cell cancers, and was absent in the poorly differentiated subtype. In contrast, cell proliferation, as assessed by expression of the Ki-67 protein, had an inverse correlation with differentiation in these cancers [95]. In all normal adult salivary glands, RUNX3 was detected in the nuclear and cytoplasm of both ductal and serous or mucous acinous cell, as well as in a few lymphoid cells, but not in the myoepithelial cells [96]. In adenoid cystic carcinomas (ACC), RUNX3 was detected mainly in the cytoplasm, and not in the nucleus. In cases of perineural, intraneural, and perivascular invasion in ACC, both tumor cells and nerve cells showed RUNX3 cytoplasmic immunopositivity. ACC cells in tumors invading the normal salivary gland tissue displayed cytoplasmic mislocalization or even loss of RUNX3 expression, indicating RUNX3 inactivation in the invasive ACC cells [96]. Similar to BCCs of the skin, Tsunematsu et al (2009) demonstrated an oncogenic role of RUNX3 in head and neck squamous cell carcinomas (HNSCCs) [35]. Compared to normal oral mucosal cells in which only a few basal epithelial cells expressed nuclear RUNX3, most primary HNSCC tissue cells overexpressed nuclear RUNX3 protein, also confirmed by fractionated-western blot analysis in HNSCC cell lines [35]. Further, the authors showed that ectopic RUNX3 overexpression promoted cell growth and inhibited serum starvation-induced apoptosis and chemotherapeutic drug induced apoptosis in HNSCC cells, confirmed by RUNX3 knockdown models. Moreover, RUNX3 overexpression enhanced tumorsphere formation [35]. All these findings suggested RUNX3 as a potential oncogene in HNSCCs. It is interesting to speculate that this distinct oncogenic function in HNSCCs and skin BCCs may be accounted for by the pathogenesis of both types of cancer, which arise from squamous epithelium. 


\section{The RUNX3 promoter}

The regulation of $R U N X 3$ by two promoters may influence its epigenetic silencing. The P2 promoter is located within a conserved $\mathrm{CpG}$ island (4. $2 \mathrm{~kb}$ ), while the $\mathrm{P} 1$ promoter occurs in a CpG-poor environment [97], and is hence unlikely to be a target of methylation. RUNX3 methylation is reported to occur initially in a high frequency (96\%) of neoplastic and non-neoplastic gastric mucosas, in the 5'-most region of the promoter, and to spread to the transcription start site, where it is relatively less frequent (53\% of gastric cancers and $11 \%$ of non-neoplastic gastric mucosas), but is specific and critical for gene silencing [109]. Thus, analysis of $R U N X 3$ methylation at multiple regions within the $R U N X 3$ CpG island may be used to assess the risk for gastric cancer.

\section{Anti-RUNX3 antibodies}

Some controversial reports have questioned the role of $R U N X 3$ as a tumor suppressor in gastrointestinal carcinogenesis, largely due to the failure to demonstrate RUNX3 expression in the gastrointestinal epithelium [110]. This discrepancy partially stemmed from the use of a specific RUNX3 antibody (G-poly), originally used by Levanon et al. (2001), to detect the Runx3 protein in mice [111]. Recently, we resolved this controversy by a comparative validation of G-poly versus a panel of in-house generated anti-RUNX3 mouse clones (R3-1E10, R3-3F12, R3-10C7 and R3-8C9) and a commercial polyclonal RUNX3 rabbit antibody (Active Motif) [104] in mouse gastrointestinal cells [112]. Monoclonal antibodies R3-1E10, R3-3F12, R3-10C7 and R3-8C9 reacted only with RUNX3/Runx3. In contrast, G-poly reacted with RUNX3/Runx3 most strongly, but also cross-reacted significantly with RUNX1/Runx1 and RUNX2/Runx2. The antibodies recognizing the RUNX3 N-terminal region (residues 1-234: R3-1E10 and R3-3F12 detected RUNX3 region 188-234; Active Motif detected RUNX3 region 28 to 53) reacted with gastric epithelial cells immunohistochemically, whereas those recognizing the C-terminal region (beyond residue 234) such as R3-10C7, R3-8C9, and G-poly did not [112]. This pattern suggests that the C-terminal region of Runx3 in the gastrointestinal epithelium is specifically modified or masked by cellular proteins that bind to Runx3 only in this tissue. 


\section{Clinical and morphomolecular correlates of RUNX3}

In gastric cancers, the intestinal rather than the diffuse type exhibits frequent $R U N X 3$ hypermethylation [98]. RUNX3 hypermethylation was associated with nuclear MSI-high (nMSI-H) and mitochondrial MSI (mtMSI) status, suggesting that $R U N X 3$ is an important epigenetic target in the evolution of nMSI-H and mtMSI gastric cancers [99]. Also, RUNX3 expression correlated with the chief cell phenotype [100] and intestinal phenotype [101] in gastric cancers. In CRCs, the poorly differentiated carcinomas displayed more frequent $R U N X 3$ hypermethylation than did the well-differentiated ones [102]. RUNX3 hypermethylation was more frequent in MSI-high than in microsatellite stable (MSS) CRCs [14]. Furthermore, transforming growth factor- $\beta$ receptor type II (TGFBR2) mutations correlated directly with CIMP-high status, and indirectly with RUNX3 hypermethylation in MSI-H sporadic CRCs [103]. Unlike CRCs, well-differentiated ESCCs exhibited more RUNX3 hypermethylation than did moderately and poorly differentiated ones [70]. RUNX3 and CDKN2A methylation were higher in EACs than in high grade-dysplastic Barrett's [71]. In breast cancers, RUNX3 hypermethylation correlated with ER [27, 30] and PR [30] positivity in hormone-receptive cancers. This correlation of $R U N X 3$ methylation with ER reactivity may possibly be attributed to ER-induced $R U N X 3$ hypermethylation, as discussed earlier. In HNSCCs, frequent RUNX3 expression correlated with malignant behavior such as poor differentiation, invasiveness and metastasis [35]. In HCCs, RUNX3 hypermethylation was frequently found in HCV-positive tissues [72,75]. Furthermore, we observed that nuclear RUNX3 expression in HCCs correlated significantly with alcohol use $(\mathrm{p}=0.039)$ (T Quek, unpublished data). HCCs associated with alcoholism have significantly more alterations of the Rb1 and p53 pathways than do those caused by $\mathrm{HCV}$ [113]. It is interesting to speculate about the possible link between TGF- $\beta /$ RUNX3 and Rb1 and p53, in the context of HCC. In bladder tumors, methylation of $R U N X 3$ increases with age and occurs at an early stage of tumorigenesis. RUNX3 methylation may be used as a "molecular clock" to determine the "age" of the tumors. Using the $R U N X 3$ methylation-based molecular clock, bladder cancers in smokers are "older" than those of non-smokers [82]. It is possible that the tumors of smokers divide quickly and accumulate more methylation errors than do those of non-smokers, or that the tumors of smokers are initiated at an earlier age. 
A summary of the clinical and morphomolecular association between RUNX3 and different cancer types is provided in Table 2.

\section{Prognostic associations of $R U N X 3$}

RUNX3 inactivation has been frequently, but not unequivocally, linked with a poor prognosis of esophageal [68-70], gastric [101,104, 116], colonic [106] and lung cancers $[87,89,90]$ (Table 3).

In gastric cancers, positive RUNX3 expression correlated with longer overall survival, whereas loss of expression correlated with poor survival $[104,116]$. In CRCs, RUNX3 (as one of the component of the CIMP panel of genes) hypermethylation; correlated with poor survival of patients suffering from MSS tumors [105]. Reduced expression of active RUNX3 protein in the nucleus, and increased amounts of inactive RUNX3 protein mislocalized to the cytoplasm were frequently detected in the advanced stages (III/IV) of CRCs [106]. In bladder cancers, RUNX3 hypermethylation is associated with a 100 -fold increase in cancer risk, tumor stage and recurrence [80]. It also appears to be associated with muscle invasion, tumor progression and overall and cancer-specific survival [81]. In ESCCs, RUNX3 had a significant impact on patient prognosis, with worse survival in the RUNX3-negative group [68, 70]. In early ESCCs (stage T1/T2), the prevalence of lymph vessel invasion and the number of metastatic lymph nodes were significantly higher in RUNX3-negative tumors [68]. Loss of RUNX3 expression also correlated with poor survival in breast [66] and oral [95] cancers and in ACC of the salivary gland [96].

\section{Diagnostic and predictive implications}

The key feature in favor of including $R U N X 3$ in a diagnostic or predictive panel of cancer biomarkers is the high specificity of RUNX3 inactivation in tumor tissues relative to normal tissues. Loss of RUNX3 expression, specifically in breast cancers [20,30], and its positive expression in normal/benign breast tissues [20,30] suggest that RUNX3 is a potential immunohistochemical marker for use in diagnostic histopathology. As a predictive marker, assessment of RUNX3 expression in pretreatment esophageal biopsies of ESCC may predict a patient's sensitivity to radiotherapy [69]. Genetic variants of $R U N X 3$ (single-nucleotide polymorphisms; SNPs) have been associated with smoking and risk prediction 
in primary urinary bladder cancers [115]. The SNP7 rs760805 AA genotype is linked to carcinogenic risk. Multifactor dimensionality reduction analysis identified SNP3 rs11249206, SNP5 rs1395621, SNP7 rs760805, SNP8 rs2236852 and the trichotomized cumulative smoking as five factors best associated with a more than six-fold risk for bladder cancer [115]. Besides bladder cancers, based on a single-locus analysis, RUNX3 SNPs such as SNP3 rs11249206 CC, SNP7 rs760805 AA and SNP8 rs2236852 GG were found to be associated with increased gastric cancer risk in a Chinese population [117]. A further combined analyses of these three SNPs revealed that the combined genotypes with four to six variant (risk) alleles (SNP3 C, SNP7 A, and SNP8 G alleles) were associated with an increased risk of gastric cancer compared with those with one to three variant (risk) alleles and this risk was more specifically observed among patient groups of age $>/=65$ years, never smokers and drinkers [117]. Other implications of $R U N X 3$ in cancer detection and prediction include the following: Methylation of $R U N X 3$ as a part of an 11-gene panel was detected in urine sediments of bladder cancer patients. Seventy-five percent of stage 0a and $88 \%$ of stage 1 diseases were detected by methylation-specific PCR for this set of genes [83]. Since RUNX3 hypermethylation is an early event in tumorigenesis, its detection in urine or biopsy specimens could serve as a marker to screen at-risk populations of cigarette smokers before onset of any symptoms [82]. Frequent $R U N X 3$ methylation in colorectal polyps could suggest its possible inclusion in the currently existing panel of epigenetic markers (CDKN2A, MGMT, MLH1, SFRP2) for detection of CRCs and its precursors from fecal samples [118].

\section{Therapeutic implications}

Reversal of DNA methylation by demethylating agents and inhibitors of DNA-methyltransferases (DNMTs) restores gene expression and function. Using either genetic or small interfering ribonucleic acid (siRNA)-mediated knockout strategies, inhibition of DNMT1 has been found to demethylate and reactivate $R U N X 3$, as well as the cancer-related genes, CDKN2A, RASSF1A, HTLF and $A K A P 12 B$, in gastric cancer cells [119]. Runx3 expression was noted to be reduced in Dnmt3b overexpressing transgenic $\mathrm{Apc}^{\mathrm{Min} /+}$ mice, which showed increased tumorigenesis [120]. It is interesting to speculate that if Runx 3 were a target of Dnmt3b, then targeted-inhibition of Dnmt3b would be a promising 
therapy for arresting CRC progression at its early stages (Figure 3A). RUNX3-negative gastric cancer cell lines treated with Vorinostat (suberoylanilide hydroxamic acid), a new class of HDAC inhibitor, reactivated $R U N X 3$, causing inhibition of tumor growth and apoptosis induction [121]. Enforced RUNX3 expression in gastric cancer cell lines caused downregulation of cyclin D1 and upregulation of p27, and caspases 3,7 and 8, leading to apoptosis and eventual inhibition of tumor growth and metastasis [104, 116]. Furthermore, RUNX3 is a marker of chemosensitivity. RUNX3 overexpression sensitized gastric cancer cells to chemotherapeutic drugs by downregulating Bcl-2, MDR-1, and MRP-1[122], while in HCC, RUNX3 in combination with adriamycin enhanced caspase-8 and inhibited Bcl-2 and suppressed tumor growth in vivo and in vitro [123]. Similar observations were also noted with CRCs [114]. Together, the above results suggest that $R U N X 3$ may be an effective therapeutic target for gastric, hepatic and colonic cancers.

\section{Future perspectives}

The RUNX family of genes, RUNX1, RUNX2 and RUNX3, are heavily involved in the cancer process [125]. In mouse model systems, Runx family genes are known to act as dominant oncogenes. Ectopic expression of Runx genes might perturb cell differentiation but lead to growth arrest, and it seems that full oncogenic transformation can only take place when overexpression of Runx genes is combined with alterations in the growth-arrest pathway or when Runx genes collaborate with other oncogenes. Interestingly, overexpression of RUNX3 was observed in BCC, a type of skin cancer known to be associated with deregulated Sonic hedgehog signaling, in which $\beta$-catenin was concomitantly found to accumulate in nuclei [34]. This observation suggests that overexpressed RUNX3 has an oncogenic influence in the aberrant signaling of hedgehog and Wnt. Mutations of the genes encoding components of various signaling pathways, including Notch, Wnt, Hedgehog, TGF $\beta /$ BMPs, and RTKs, have been associated with cancers, either as oncogenes (dominant-active versions of the proteins) or as tumor suppressor genes (revealed as recessive mutations) [126]. RUNX3 is a novel node between tumor suppressive TGF $\beta / B M P$ s and oncogenic Wnt signaling [32], both of which are known to regulate the function and development of adult epithelial stem cells and so-called cancer stem cells. To maintain stem cell functions, multipotency and self-renewal capacity in the microenvironment, RUNX3 might have to 
behave as an oncoprotein in a context-dependent manner.

\section{Conclusions}

RUNX3 is deeply involved in multiple cancer processes, such as cell growth, apoptosis, angiogenesis, metastasis, most likely epithelial-mesenchymal transition (EMT), and cancer stem cell development, in various types of tissues. Identification of key tissue- and stage-specific target genes of RUNX3 functioning as a tumor suppressor or an oncogene is an important step forward, and combination of these genes would improve the potential of usage of RUNX3 as a biomarker for cancer diagnosis. An understanding of the upstream and downstream signaling pathways of RUNX3 in the context of physiological and pathological processes is indispensable if we are to harness our growing knowledge of RUNX3 for successful applications in cancer therapeutics. 


\section{Acknowledgements}

We thank all the authors for their valuable contributions in the field of RUNX3 in human neoplasia, without which this review would not have been possible. We also apologize to all the authors whose work could not be included in this manuscript owing to space constraints.

\section{Financial support}

M Salto-Tellez receives funding support from SCS Grants MN-05 \& MN-77, awarded by the Singapore Cancer Syndicate, Agency for Science, Technology and Research, Singapore

\section{Competing interests}

None of the authors have any competing interest to be declared. 


\section{References}

[1] A.J. van Wijnen, G.S. Stein, J.P. Gergen, Y.Groner, S.W. Hiebert, Y. Ito, P.Liu, J.C. Neil, M. Ohki, N. Speck, Nomenclature for Runt-related (RUNX) proteins. Oncogene 23(2004) 4209-4210.

[2]T. Okuda, J. van Deursen, S.W. Hiebert, G. Grosveld, J.R. Downing, AML1, the target of multiple chromosomal translocations in human leukemia, is essential for normal fetal liver hematopoiesis. Cell 84 (1996) 321-330.

[3] Q. Wang, T. Stacy, M. Binder, M. Marin-Padilla, A.H. Sharpe, N.A. Speck, Disruption of the Cbfa2 gene causes necrosis and hemorrhaging in the central nervous system and blocks definitive hematopoiesis. Proc. Natl. Acad. Sci. USA 93(1996) 3444-3449.

[4] A.T. Look, Oncogenic transcription factors in the human acute leukemias. Science 278(1997) 1059-1064.

[5] T. Komori, H. Yagi, S. Nomura, A. Yamaguchi, K. Sasaki, K. Deguchi, Y. Shimizu, R.T. Bronson, Y.H. Gao, M. Inada, M. Sato, R. Okamoto, Y. Kitamura, S. Yoshiki, T. Kishimoto, Targeted disruption of Cbfal results in a complete lack of bone formation owing to maturational arrest of osteoblasts. Cell 89(1997) 755-764.

[6] F. Otto, A. P. Thornell, T. Crompton, A. Denzel, K.C. Gilmour, I.R. Rosewell, G.W. Stamp, R.S. Beddington, S. Mundlos, B.R. Olsen, P.B. Selby, M.J. Owen, Cbfa1, a candidate gene for cleidocranial dysplasia syndrome, is essential for osteoblast differentiation and bone development. Cell 89(1997) 765-771.

[7] S. Mundlos, F. Otto, C. Mundlos, J.B. Mulliken, A.S. Aylsworth, S. Albright, D. Lindhout, W.G.Cole, W. Henn, J.H. Knoll, M.J. Owen, R. Mertelsmann, B.U. Zabel, B.R. Olsen, Mutations involving the transcription factor CBFA1 cause cleidocranial dysplasia. Cell 89(1997) 773-779.

[8] Q.L. Li, K.Ito, C. Sakakura, H. Fukamachi, K.Inoue, X.Z. Chi, K.Y. Lee, S. Nomura, C.W. Lee, S.B. Han, H.M. Kim, W.J. Kim, H.Yamamoto, N. Yamashita, T. Yano, T. Ikeda, S. Itohara, J. Inazawa, T. Abe, A. Hagiwara, H. Yamagishi, A. Ooe, A. Kaneda, T. Sugimura, T. Ushijima, S.C. Bae, Y.Ito, Causal relationship between the loss of RUNX3 expression and gastric cancer. Cell 109(2002) 113-124. 
[9] K. Inoue, S. Ozaki, T. Shiga, K.Ito, T. Masuda, N. Okado, T. Iseda, S. Kawaguchi, M. Ogawa, S.C.

Bae, N. Yamashita, S. Itohara, N. Kudo, Y. Ito, Runx3 controls the axonal projection of proprioceptive dorsal root ganglion neurons. Nat. Neurosci. 5(2002) 946-954.

[10] D. Levanon, D. Bettoun, C. Harris-Cerruti, E. Woolf, V. Negreanu, R. Eilam, Y. Bernstein, D. Goldenberg, C. Xiao, M. Fliegauf, E. Kremer, F.Otto, O. Brenner, A. Lev-Tov, Y. Groner, D. Levanon, The Runx 3 transcription factor regulates development and survival of TrkC dorsal root ganglia neurons. EMBO J. 21(2002)3454-3463.

[11] I. Taniuchi, M. Osato, T. Egawa, M.J. Sunshine, S.C. Bae, T. Komori, Y.Ito, D.R. Littman, Differential requirements for Runx proteins in CD4 repression and epigenetic silencing during $\mathrm{T}$ lymphocyte development. Cell 111(2002) 621-633.

[12] K. Schulmann, A. Sterian, A. Berki, J.Yin, F. Sato, Y. Xu, A. Olaru, S. Wang, Y. Mori, E. Deacu, J. Hamilton, T. Kan, M.J. Krasna, D.G. Beer, M.S. Pepe, J.M. Abraham, Z. Feng, W. Schmiegel, B.D. Greenwald, S.J. Meltzer, Inactivation of p16, RUNX3, and HPP1 occurs early in Barrett's-associated neoplastic progression and predicts progression risk. Oncogene $24(2005) 4138-4148$.

[13] K. Ito, Q. Liu, M. Salto-Tellez, T. Yano, K. Tada, H. Ida, C. Huang, N.Shah, M. Inoue, A. Rajnakova, K.C. Hiong, B.K. Peh, H.C. Han, T. Ito, M. Teh, K.G. Yeoh, Y. Ito, RUNX3, a novel tumor suppressor, is frequently inactivated in gastric cancer by protein mislocalization. Cancer Res. 65(2005)7743-7750.

[14] A. Goel, C.N. Arnold, P. Tassone, D.K. Chang, D. Niedzwiecki, J.M. Dowell, L. Wasserman, C. Compton, R.J. Mayer, M.M. Bertagnolli, C.R. Boland, Epigenetic inactivation of RUNX3 in microsatellite unstable sporadic colon cancers., Int. J. Cancer 112(2004) 754-759.

[15] T.Y. Kim, H.J. Lee, K.S. Hwang, M. Lee, J.W. Kim, Y.J. Bang, G.H. Kang, Methylation of RUNX3 in various types of human cancers and premalignant stages of gastric carcinoma. Lab. Invest. 84(2004)479-484.

[16] T. Takahashi, N. Shivapurkar, E. Riquelme, H. Shigematsu, J. Reddy, M. Suzuki, K. Miyajima, X. Zhou, B.N. Bekele, A.F. Gazdar, I.I. Wistuba, Aberrant promoter hypermethylation of multiple genes in gallbladder carcinoma and chronic cholecystitis. Clin. Cancer Res. 10(2004) 6126-6133. 
[17] T. Tozawa, G.Tamura, T. Honda, S. Nawata, W. Kimura, N. Makino, S. Kawata, T. Sugai, T. Suto, T. Motoyama, Promoter hypermethylation of DAP-kinase is associated with poor survival in primary biliary tract carcinoma patients. Cancer Sci. 95(2004) 736-740.

[18] M. Wada, S. Yazumi, S. Takaishi, K.Hasegawa, M. Sawada, H. Tanaka, H.Ida, C. Sakakura, K. Ito, Y. Ito, T. Chiba, Frequent loss of RUNX3 gene expression in human bile duct and pancreatic cancer cell lines. Oncogene 23(2004) 2401-2407.

[19] W.J. Kim, E.J. Kim, P. Jeong, C. Quan, J.Kim, Q.L. Li, J.O.Yang, Y. Ito, S.C. Bae, Cancer Res. 65 (2005) 9347-9354.

[20] Q.C. Lau, E. Raja, M. Salto-Tellez, Q. Liu, K. Ito, M. Inoue, T.C. Putti, M.Loh, T.K. Ko, C.Huang, K.N. Bhalla, T. Zhu, Y. Ito, S. Sukumar, RUNX3 is frequently inactivated by dual mechanisms of protein mislocalization and promoter hypermethylation in breast cancer. Cancer Res. 66(2006) $6512-6520$.

[21] G.H. Kang, S. Lee, H.J. Lee, K.S. Hwang, Aberrant CpG island hypermethylation of multiple genes in prostate cancer and prostatic intraepithelial neoplasia. J Pathol. 202 (2004) 233-240.

[22] V.S. Dhillon, M. Shahid, S.A. Husain, CpG methylation of the FHIT, FANCF, cyclin-D2, BRCA2 and RUNX3 genes in Granulosa cell tumors (GCTs) of ovarian origin. Mol. Cancer. 3(2004) 33.

[23] N.S. Nevadunsky, J.S. Barbieri, J. Kwong, M.A. Merritt, W.R. Welch, R.S. Berkowitz, S.C. Mok, RUNX3 protein is overexpressed in human epithelial ovarian cancer. Gynecol. Oncol. 112(2009) 325-330.

[24] N. Kato, G. Tamura, M. Fukase, H. Shibuya, T. Motoyama. Hypermethylation of the RUNX3 gene promoter in testicular yolk sac tumor of infants. Am. J. Pathol. 163(2003) 387-391.

[25] T. Yoshizaki, T. Enomoto, M. Fujita, Y. Ueda, T. Miyatake, K. Fujiwara, T. Miyake, T. Kimura, K. Yoshino, T. Kimura, Frequent inactivation of RUNX3 in endometrial carcinoma. Gynecol .Oncol. $110(2008) 439-444$.

[26] N. Yanagawa, G. Tamura, H. Oizumi, N.Takahashi, Y. Shimazaki, T. Motoyama, Promoter hypermethylation of tumor suppressor and tumor-related genes in non-small cell lung cancers. Cancer. Sci. 94(2003) 589-592. 
[27] M. Suzuki, H. Shigematsu, D.S. Shames, N. Sunaga, T. Takahashi, N. Shivapurkar, T. Iizasa, E.P. Frenkel, J.D. Minna, T. Fujisawa, A.F. Gazdar, DNA methylation-associated inactivation of TGFbeta-related genes DRM/Gremlin, RUNX3, and HPP1 in human cancers. Br. J. Cancer. 93(2005)1029-1037.

[28] W. Mueller, C.L. Nutt, M. Ehrich, M.J. Riemenschneider, A. von Deimling, D. van den Boom, D.N. Louis, Downregulation of RUNX3 and TES by hypermethylation in glioblastoma. Oncogene 26(2007) 583-593.

[29] S.H. Tan, H. Ida, Q.C. Lau, B.C. Goh, W.S. Chieng, M. Loh, Y. Ito, Detection of promoter hypermethylation in serum samples of cancer patients by methylation-specific polymerase chain reaction for tumour suppressor genes including RUNX3. Oncol. Rep. 18 (2007) 1225-1230.

[30] M.M. Subramaniam, J.Y. Chan, R. Soong, K. Ito, Y. Ito, K.G.Yeoh, M. Salto-Tellez, T.C. Putti, RUNX3 inactivation by frequent promoter hypermethylation and protein mislocalization constitute an early event in breast cancer progression. Breast. Cancer. Res. Treat. 113(2009) 113-121.

[31] Subramaniam MM, Chan JY, Soong R, Ito K, Yeoh KG, Wong R, Guenther T, Will O, Chen CL, Kumarasinghe MP, Ito Y, Salto-Tellez M. RUNX3 inactivation in colorectal polyps arising through different pathways of colonic carcinogenesis. Am. J. Gastroenterol. 104(2009) 426-436.

[32] K. Ito, A.C. Lim, M. Salto-Tellez, L. Motoda, M. Osato, L.S. Chuang, C.W. Lee, D.C. Voon, J.K. Koo, H. Wang, H. Fukamachi, Y. Ito, RUNX3 attenuates beta-catenin/T cell factors in intestinal tumorigenesis. Cancer. Cell. 14(2008) 226-237.

[33] L.C. Spender, G.H. Cornish, A. Sullivan, P.J. Farrell, Expression of transcription factor AML-2 (RUNX3, CBF(alpha)-3) is induced by Epstein-Barr virus EBNA-2 and correlates with the B-cell activation phenotype. J. Virol.76(2002) 4919-4927.

[34] M. Salto-Tellez, B.K. Peh, K. Ito, S.H. Tan, P.Y. Chong, H.C. Han, K. Tada, W.Y. Ong, R. Soong, D.C. Voon, Y. Ito, RUNX3 protein is overexpressed in human basal cell carcinomas. Oncogene 25(2006) 7646-7649.

[35] Tsunematsu T, Kudo Y, Iizuka S, Ogawa I, Fujita T, Kurihara H, Abiko Y, Takata T. RUNX3 has an oncogenic role in head and neck cancer. PLoS One. 12 (2009) e5892 
[36] Y.Tanaka, J. Imamura, F. Kanai, T. Ichimura, T. Isobe, M. Koike, Y. Kudo, K. Tateishi, T. Ikenoue, H. Ijichi, Y. Yamaji, H. Yoshida, T. Kawabe, M. Omata, Runx3 interacts with DNA repair protein ku70. Exp. Cell. Res. 313(2007) 3251-3260.

[37] Z. Peng, D.Wei, L.Wang, H.Tang, J.Zhang, X. Le, Z. Jia, Q. Li, K. Xie, RUNX3 inhibits the expression of vascular endothelial growth factor and reduces the angiogenesis, growth, and metastasis of human gastric cancer. Clin. Cancer Res. 12(2006) 6386-6394.

[38] C. Sakakura, K. Hasegawa, K. Miyagawa, S. Nakashima, T.Yoshikawa, S. Kin, Y. Nakase, S. Yazumi, H. Yamagishi, T. Okanoue, T. Chiba, A. Hagiwara, Possible involvement of RUNX3 silencing in the peritoneal metastases of gastric cancers. Clin. Cancer. Res. 11(2005) 6479-6488.

[39] A. Weith, G.M. Brodeur, G.A. Bruns, T.C. Matise, D. Mischke, D. Nizetic, M.F. Seldin, N. van Roy, J. Vance. Report of the second international workshop on human chromosome 1 mapping. Cytogenet. Cell. Genet. 72(1995) 114-144.

[40] Y. Ito, K. Miyazono, RUNX transcription factors as key targets of TGF-beta superfamily signaling. Curr. Opin. Genet. Dev. 13(2003) 43-47.

[41] X.Z. Chi, J.O. Yang, K.Y. Lee, K. Ito, C. Sakakura, Q.L. Li, H.R. Kim, E.J. Cha, Y.H. Lee, A. Kaneda, T. Ushijima, W.J. Kim, Y. Ito, S.C. Bae, RUNX3 suppresses gastric epithelial cell growth by inducing p21(WAF1/Cip1) expression in cooperation with transforming growth factor $\{$ beta $\}$-activated SMAD. Mol. Cell. Biol. 25(2005)8097-8107.

[42] Y.Yamamura, W.L. Lee, K. Inoue, H. Ida, Y.Ito, RUNX3 cooperates with FoxO3a to induce apoptosis in gastric cancer cells. J. Biol. Chem. 281(2006) 5267-5276.

[43] T. Yano, K. Ito, H. Fukamachi, X.Z. Chi, H.J. Wee, K. Inoue, H. Ida, P. Bouillet, A. Strasser, S.C. Bae, Y. Ito, The RUNX3 tumor suppressor upregulates Bim in gastric epithelial cells undergoing transforming growth factor beta-induced apoptosis. Mol. Cell. Biol. 26(2006) 4474-4488.

[44] N. Saeki, Y. Kuwahara, H. Sasaki, H. Satoh, T. Shiroishi, Gasdermin (Gsdm) localizing to mouse Chromosome 11 is predominantly expressed in upper gastrointestinal tract but significantly suppressed in human gastric cancer cells. Mamm. Genome. 11(2000) 718-724.

[45] N. Saeki, D.H. Kim, T. Usui, K. Aoyagi, T. Tatsuta, K. Aoki, K. Yanagihara, M. Tamura, H. Mizushima, H. Sakamoto, K.Ogawa, M. Ohki, T. Shiroishi, T. Yoshida, H. Sasaki. GASDERMIN, 
suppressed frequently in gastric cancer, is a target of LMO1 in TGF-beta-dependent apoptotic signalling. Oncogene. 26(2007) 6488-6498.

[46] Y. Nagahama, M. Ishimaru, M. Osaki, T. Inoue, A. Maeda, C. Nakada, M. Moriyama, K. Sato, M. Oshimura, H. Ito, Apoptotic pathway induced by transduction of RUNX3 in the human gastric carcinoma cell line MKN-1. Cancer. Sci. 99(2008) 23-30.

[47] S.H. Lee, J. Kim, W.H. Kim, Y.M. Lee, Hypoxic silencing of tumor suppressor RUNX3 by histone modification in gastric cancer cells. Oncogene 28(2009) 184-194.

[48] S. Fujii, K. Ito, Y. Ito, A. Ochiai, Enhancer of zeste homologue 2 (EZH2) down-regulates RUNX3 by increasing histone H3 methylation. J. Biol. Chem. 283(2008) 17324-17332.

[49] J.H. Kim, J.K. Choi, S. Cinghu, J.W. Jang, Y.S. Lee, Y.H. Li, Y.M. Goh, X.Z. Chi, K.S. Lee, H. Wee, S.C. Bae, Jab1/CSN5 induces the cytoplasmic localization and degradation of RUNX3. J Cell Biochem. 107 (2009) 557-565.

[50] H.R. Kim, B.C. Oh, J.K. Choi, S.C. Bae, Pim-1 kinase phosphorylates and stabilizes RUNX3 and alters its subcellular localization. J. Cell. Biochem. 105(2008) 1048-1058.

[51] A.O. Chan, S.K. Lam, B.C. Wong, W.M. Wong, M.F. Yuen, Y.H. Yeung, W.M. Hui, A. Rashid, Y.L. Kwong, Promoter methylation of E-cadherin gene in gastric mucosa associated with Helicobacter pylori infection and in gastric cancer. Gut 52(2003) 502-506.

[52] T. Maekita, K. Nakazawa, M. Mihara, T. Nakajima, K. Yanaoka, M. Iguchi, K. Arii, A. Kaneda, T. Tsukamoto, M. Tatematsu, G. Tamura, D. Saito, T. Sugimura, M. Ichinose, T. Ushijima, High levels of aberrant DNA methylation in Helicobacter pylori-infected gastric mucosae and its possible association with gastric cancer risk. Clin. Cancer. Res. 12(2006) 989-995.

[53] T. Nakajima, S. Yamashita, T. Maekita, T. Niwa, K. Nakazawa, T. Ushijima, The presence of a methylation fingerprint of Helicobacter pylori infection in human gastric mucosae. Int. J. Cancer. 124(2009) 905-910.

[54] Y. Kitajima, K. Ohtaka, M. Mitsuno, M. Tanaka, S. Sato, Y. Nakafusa, K. Miyazaki, Helicobacter pylori infection is an independent risk factor for RUNX3 hypermethylation in gastric cancer. Oncol. Rep. 19(2008)197-202. 
[55] T. Waki, G. Tamura, M. Sato, M. Terashima, S. Nishizuka, T. Motoyama, Promoter methylation status of DAP-kinase and RUNX3 genes in neoplastic and non-neoplastic gastric epithelia. Cancer. Sci. 94(2003) 360-364.

[56] Y. Nakase, C. Sakakura, K. Miyagawa, S. Kin, K. Fukuda, A. Yanagisawa, K. Koide, N. Morofuji, Y. Hosokawa, K. Shimomura, K. Katsura, A. Hagiwara, H. Yamagishi, K. Ito, Y. Ito, Frequent loss of RUNX3 gene expression in remnant stomach cancer and adjacent mucosa with special reference to topography. Br. J. Cancer. 92(2005) 562-569.

[57] H. Fukamachi, A. Mimata, I. Tanaka, K. Ito, Y. Ito, Y. Yuasa, In vitro differentiation of Runx3-/p53-/- gastric epithelial cells into intestinal type cells. Cancer. Sci. 99(2008) 671-676.

[58] H. Fukamachi, K. Ito, Y. Ito, Runx3-/- gastric epithelial cells differentiate into intestinal type cells. Biochem. Biophys. Res. Commun. 321(2004) 58-64.

[59] B. Vogelstein, E.R. Fearon, S.R. Hamilton, S.E. Kern, A.C. Preisinger, M. Leppert, Y. Nakamura, R. White, A.M. Smits, J.L. Bos, Genetic alterations during colorectal-tumor development. N. Engl. J. Med. 319(1988) $525-532$.

[60] P.C. Chen, M. Kuraguchi, J. Velasquez, Y. Wang, K. Yang, R. Edwards, D. Gillen, W. Edelmann, R. Kucherlapati, S.M. Lipkin, Novel roles for MLH3 deficiency and TLE6-like amplification in DNA mismatch repair-deficient gastrointestinal tumorigenesis and progression. PLoS. Genet. 4(2008) $\mathrm{e} 1000092.22$

[61] J.R. Jass, Serrated adenoma of the colorectum and the DNA-methylator phenotype. Nat. Clin. Pract. Oncol. 2(2005) 398-405.

[62] D.J. Weisenberger, K.D. Siegmund, M. Campan, J. Young, T.I. Long, M.A. Faasse, G.H. Kang, M. Widschwendter, D. Weener, D. Buchanan, H. Koh, L. Simms, M. Barker, B. Leggett, J. Levine, M. Kim, A.J. French, S.N. Thibodeau, J. Jass, R. Haile, P.W. Laird, CpG island methylator phenotype underlies sporadic microsatellite instability and is tightly associated with BRAF mutation in colorectal cancer. Nat. Genet. 38(2006) 787-793.

[63] W. Chen, M. Salto-Tellez, N. Palanisamy, K. Ganesan, Q. Hou, L.K. Tan, L.H. Sii, K. Ito, B. Tan, J. Wu, A. Tay, K.C. Tan, E. Ang, B.K. Tan, P.H. Tan, Y. Ito, P. Tan, Targets of genome copy 
number reduction in primary breast cancers identified by integrative genomics. Genes. Chromosomes. Cancer. 46(2007) 288-301.

[64] K.T. Hwang, W. Han, J.Y. Bae, S.E. Hwang, H.J. Shin, J.E. Lee, S.W. Kim, H.J. Min, D.Y. Noh, Downregulation of the RUNX3 gene by promoter hypermethylation and hemizygous deletion in breast cancer. J. Korean. Med. Sci. 22 (2007) Suppl:S24-31

[65] A.S. Cheng, A.C. Culhane, M.W. Chan, C.R. Venkataramu, M. Ehrich, A. Nasir, B.A. Rodriguez, J. Liu, P.S. Yan, J. Quackenbush, K.P. Nephew, T.J. Yeatman, T.H. Huang, Epithelial progeny of estrogen-exposed breast progenitor cells display a cancer-like methylome. Cancer Res. 68(2008) 1786-1796.

[66] Y. Jiang, D. Tong, G. Lou, Y. Zhang, J. Geng, Expression of RUNX3 gene, methylation status and clinicopathological significance in breast cancer and breast cancer cell lines. Pathobiology $75(2008) 244-251$.

[67] A. Torquati, L. O'rear, L. Longobardi, A. Spagnoli, W.O. Richards, R. Daniel Beauchamp, RUNX3 inhibits cell proliferation and induces apoptosis by reinstating transforming growth factor beta responsiveness in esophageal adenocarcinoma cells. Surgery. 136 (2004) 310-316.

[68] Y. Tonomoto, M. Tachibana, D.K. Dhar, T. Onoda, K. Hata, H. Ohnuma, T. Tanaka, N. Nagasue, Differential expression of RUNX genes in human esophageal squamous cell carcinoma: downregulation of RUNX3 worsens patient prognosis. Oncology 73(2007) 346-356.

[69] C. Sakakura, K. Miyagawa, K.I. Fukuda, S. Nakashima, T. Yoshikawa, S. Kin, Y. Nakase, H. Ida, S. Yazumi, H. Yamagishi, T. Okanoue, T. Chiba, K. Ito, A. Hagiwara, Y. Ito, Frequent silencing of RUNX3 in esophageal squamous cell carcinomas is associated with radioresistance and poor prognosis. Oncogene 26(2007) 5927-5938.

[70] T. Hiramatsu, M. Osaki, Y. Ito, Y. Tanji, N. Tokuyasu, H. Ito. Expression of RUNX3 protein in human esophageal mucosa and squamous cell carcinoma. Pathobiology 72(2005) 316-324.

[71] E. Smith, N.J. De Young, S.J. Pavey, N.K. Hayward, D.J. Nancarrow, D.C. Whiteman, B.M. Smithers, A.R. Ruszkiewicz, A.D. Clouston, D.C. Gotley, P.G. Devitt, G.G. Jamieson, P.A. Drew, Similarity of aberrant DNA methylation in Barrett's esophagus and esophageal adenocarcinoma. Mol. Cancer. 7(2008) 75. 
[72] T. Mori, S. Nomoto, K. Koshikawa, T. Fujii, M. Sakai, Y. Nishikawa, S. Inoue, S. Takeda, T. Kaneko, A. Nakao, Decreased expression and frequent allelic inactivation of the RUNX3 gene at 1p36 in human hepatocellular carcinoma. Liver. Int. 25(2005) 380-388.

[73] W.S. Park, Y.G. Cho, C.J. Kim, J.H. Song, Y.S. Lee, S.Y. Kim, S.W. Nam, S.H. Lee, N.J. Yoo, J.Y. Lee, Hypermethylation of the RUNX3 gene in hepatocellular carcinoma. Exp. Mol. Med. 37(2005) 276-281.

[74] S. Nomoto, T. Kinoshita, K. Kato, S. Otani, H. Kasuya, S. Takeda, N. Kanazumi, H. Sugimoto, A. Nakao, Hypermethylation of multiple genes as clonal markers in multicentric hepatocellular carcinoma. Br. J. Cancer. 97(2007) 1260-1265.

[75] N. Nishida, T. Nagasaka, T. Nishimura, I. Ikai, C.R. Boland, A. Goel, Aberrant methylation of multiple tumor suppressor genes in aging liver, chronic hepatitis, and hepatocellular carcinoma. Hepatology 47(2008) 908-918.

[76] T. Moribe , N. Iizuka, T. Miura, N. Kimura, S.Tamatsukuri , H. Ishitsuka, Y. Hamamoto, K. Sakamoto, T. Tamesa, M. Oka, Int. J. Cancer 125 (2009) 388-97.

[77] W.H. Xiao, W.W. Liu, Hemizygous deletion and hypermethylation of RUNX3 gene in hepatocellular carcinoma. World. J. Gastroenterol. 10(2004) 376-380.

[78] J. Li, J. Kleeff, A. Guweidhi, I. Esposito, P.O. Berberat, T. Giese, M.W. Büchler, H. Friess, RUNX3 expression in primary and metastatic pancreatic cancer. J. Clin. Pathol. 57 (2004) 294-299.

[79] S. Nomoto, T. Kinoshita, T. Mori, K. Kato, H. Sugimoto, N. Kanazumi, S. Takeda, A. Nakao, Adverse prognosis of epigenetic inactivation in RUNX3 gene at 1p36 in human pancreatic cancer. Br. J. Cancer 98 (2008) 1690-1695

[80] W.J. Kim, E.J. Kim, P. Jeong, C. Quan, J. Kim, Q.L. Li, J.O. Yang, Y. Ito, S.C. Bae, RUNX3 inactivation by point mutations and aberrant DNA methylation in bladder tumors. Cancer. Res 65(2005) 9347-9354.

[81] E.J. Kim, Y.J. Kim, P. Jeong, Y.S. Ha, S.C. Bae, W.J. Kim. Methylation of the RUNX3 promoter as a potential prognostic marker for bladder tumor. J. Urol. 180(2008) 1141-1145. 
[82] E.M. Wolff, G. Liang, C.C. Cortez, Y.C. Tsai, J.E. Castelao, V.K. Cortessis, D.D. Tsao-Wei, S. Groshen, P.A. Jones, RUNX3 hypermethylation reveals that bladder tumors are older in patients with a history of smoking. Cancer. Res 68(2008) 6208-6214.

[83] J. Yu, T. Zhu, Z. Wang, H. Zhang, Z. Qian, H. Xu, B. Gao, W. Wang, L. Gu, J. Meng, Wang J, Feng X, Li Y, Yao X, Zhu J. A novel set of DNA methylation markers in urine sediments for sensitive/specific detection of bladder cancer. Clin. Cancer. Res. 13(2007) 7296-8304.

[84] N.Y. Cho, B.H. Kim, M. Choi, E.J. Yoo, K.C. Moon, Y.M. Cho, D. Kim, G.H. Kang, Hypermethylation of $\mathrm{CpG}$ island loci and hypomethylation of LINE-1 and Alu repeats in prostate adenocarcinoma and their relationship to clinicopathological features. J. Pathol. 211(2007) 269-277.

[85] G.E. Lind, R.I. Skotheim, M.F. Fraga, V.M. Abeler, M. Esteller, R.A. Lothe, Novel epigenetically deregulated genes in testicular cancer include homeobox genes and SCGB3A1 (HIN-1). J. Pathol. 210(2006) 441-449.

[86] K. Sato, Y. Tomizawa, H. Iijima, R. Saito, T. Ishizuka, T. Nakajima, M. Mori, Epigenetic inactivation of the RUNX3 gene in lung cancer. Oncol. Rep. 15(2006)129-135.

[87] Q.L. Li, H.R. Kim, W.J. Kim, J.K. Choi, Y.H. Lee, H.M. Kim, L.S. Li, H. Kim, J. Chang, Y. Ito, K. Youl Lee, S.C. Bae. Transcriptional silencing of the RUNX3 gene by CpG hypermethylation is associated with lung cancer. Biochem. Biophys. Res. Commun. 314(2004)223-228.

[88] J.D. Licchesi, W.H. Westra, C.M. Hooker, E.O. Machida, S.B. Baylin, J.G. Herman, Epigenetic alteration of Wnt pathway antagonists in progressive glandular neoplasia of the lung. Carcinogenesis. 29(2008) 895-904.

[89] K. Araki, M. Osaki, Y. Nagahama, T. Hiramatsu, H. Nakamura, S. Ohgi, H. Ito, Expression of RUNX3 protein in human lung adenocarcinoma: implications for tumor progression and prognosis. Cancer. Sci. 96(2005) 227-231.

[90] N. Yanagawa, G. Tamura, H. Oizumi, N. Kanauchi, M. Endoh, M. Sadahiro, T. Motoyama. Promoter hypermethylation of RASSF1A and RUNX3 genes as an independent prognostic prediction marker in surgically resected non-small cell lung cancers. Lung. Cancer. 58(2007) 131-138

[91] M. Kitago, S.R. Martinez, T. Nakamura, M.S. Sim, D.S. Hoon, Regulation of RUNX3 tumor suppressor gene expression in cutaneous melanoma. Clin Cancer Res 15 (2009) 2988-2994. 
[92] J.F. Costello, M.C. Frühwald, D.J. Smiraglia, L.J. Rush, G.P.Robertson, X. Gao, F.A. Wright, J.D. Feramisco, P. Peltomäki, J.C. Lang, D.E. Schuller, L. Yu, C.D. Bloomfield, M.A. Caligiuri, A. Yates, R. Nishikawa, H. Su Huang, N.J. Petrelli, X. Zhang, M.S. O'Dorisio, W.A. Held, W.K. Cavenee, C. Plass, Aberrant CpG-island methylation has non-random and tumour-type-specific patterns. Nat .Genet. 24(2000) 132-138.

[93] L. Daya-Grosjean, S. Couvé-Privat, Sonic hedgehog signaling in basal cell carcinomas. Cancer. Lett. 225(2005) 181-192.

[94] F. Yamazaki, Y. Aragane, A. Kawada, T. Tezuka, Immunohistochemical detection for nuclear beta-catenin in sporadic basal cell carcinoma. Br. J. Dermatol. 145(2001) 771-777.

[95] Y. Tanji, M. Osaki, Y. Nagahama, I. Kodani, K. Ryoke, H. Ito, Runt-related transcription factor 3 expression in human oral squamous cell carcinomas; implication for tumor progression and prognosis. Oral. Oncol. 43(2007) 88-94.

[96] J.F. He, M.H. Ge, X. Zhu, C. Chen, Z. Tan, Y.N. Li, Z.Y. Gu, Expression of RUNX3 in salivary adenoid cystic carcinoma: implications for tumor progression and prognosis. Cancer. Sci. 99(2008) $1334-1340$.

[97] C. Bangsow, N. Rubins, G. Glusman, Y. Bernstein, V. Negreanu, D. Goldenberg, J. Lotem, E. Ben-Asher, D. Lancet, D. Levanon, Y. Groner, The RUNX3 gene-sequence, structure and regulated expression. Gene. 279(2001) 221-232.

[98] Y. Oshimo, N. Oue, Y. Mitani, H.Nakayama, Y. Kitadai, K.Yoshida, Y. Ito, K. Chayama, W. Yasui, Frequent loss of RUNX3 expression by promoter hypermethylation in gastric carcinoma. Pathobiology. 71(2004) 137-143.

[99] G. Gargano, D. Calcara, S. Corsale, V. Agnese, C. Intrivici, F. Fulfaro, G. Pantuso, M. Cajozzo, V. Morello, R.M. Tomasino, L. Ottini, G. Colucci, V. Bazan, A. Russo, Aberrant methylation within RUNX3 CpG island associated with the nuclear and mitochondrial microsatellite instability in sporadic gastric cancers. Results of a GOIM (Gruppo Oncologico dell'Italia Meridionale) prospective study. Ann Oncol. Suppl 6 (2007) vi 103-109. 
[100] N. Ogasawara, T. Tsukamoto, T. Mizoshita, K.I. Inada, H. Ban, S. Kondo, S. Takasu, T. Ushijima, K. Ito, Y. Ito, M. Ichinose, T. Ogawa, T. Joh, M. Tatematsu, RUNX3 expression correlates with chief cell differentiation in human gastric cancers. Histol. Histopathol. 24(2009) 31-40.

[101] K. Wakatsuki, Y. Yamada, M. Narikiyo, M. Ueno, T. Takayama, H. Tamaki, K. Miki, S. Matsumoto, K. Enomoto, T. Yokotani, Y. Nakajima, Clinicopathological and prognostic significance of mucin phenotype in gastric cancer. J. Surg. Oncol. 98(2008)124-129.

[102] Y. Imamura, K. Hibi, M. Koike, M. Fujiwara, Y. Kodera, K. Ito, A. Nakao, RUNX3 promoter region is specifically methylated in poorly-differentiated colorectal cancer. Anticancer Res 25(2005) $2627-2630$.

[103] S. Ogino, T. Kawasaki, A. Ogawa, G.J. Kirkner, M. Loda, C.S. Fuchs, TGFBR2 mutation is correlated with $\mathrm{CpG}$ island methylator phenotype in microsatellite instability-high colorectal cancer. Hum. Pathol. 38(2007) 614-620.

[104] D. Wei, W. Gong, S.C. Oh, Q. Li, W.D. Kim, L. Wang, X. Le, J. Yao, T.T. Wu, S. Huang, K. Xie, Loss of RUNX3 expression significantly affects the clinical outcome of gastric cancer patients and its restoration causes drastic suppression of tumor growth and metastasis. Cancer. Res 65(2005) $4809-4816$.

[105] S. Ogino, J.A. Meyerhardt, T. Kawasaki, J.W. Clark, D.P. Ryan, M.H. Kulke, P.C. Enzinger, B.M. Wolpin, M. Loda, C.S. Fuchs, CpG island methylation, response to combination chemotherapy, and patient survival in advanced microsatellite stable colorectal carcinoma. Virchows. Arch. 450(2007) $529-537$.

[106] R. Soong, N. Shah, B.K. Peh, P.Y. Chong, S.S. Ng, N. Zeps, D. Joseph, M. Salto-Tellez, B. Iacopetta, Y. Ito, The expression of RUNX3 in colorectal cancer is associated with disease stage and patient outcome. Br. J. Cancer. 100(2009) 676-679.

[107] J.L. Ku, S.B. Kang, Y.K. Shin, H.C. Kang, S.H.Hong, I.J. Kim, J.H. Shin, I.O. Han, J.G. Park, Promoter hypermethylation downregulates RUNX3 gene expression in colorectal cancer cell lines. Oncogene. 23(2004) 6736-6742. 
[108] S. Ogino, T. Kawasaki, G.J. Kirkner, P. Kraft, M. Loda, C.S. Fuchs, Evaluation of markers for CpG island methylator phenotype (CIMP) in colorectal cancer by a large population-based sample. J. Mol. Diagn. 9(2007) 305-314.

[109] N. Homma, G. Tamura, T. Honda, Y. Matsumoto, S. Nishizuka, S. Kawata, T. Motoyama, Spreading of methylation within RUNX3 CpG island in gastric cancer. Cancer. Sci. 97(2006) 51-56.

[110] R. Carvalho, A.N. Milne, M. Polak, W.E. Corver, G.J. Offerhaus, M.A. Weterman, Exclusion of RUNX3 as a tumour-suppressor gene in early-onset gastric carcinomas. Oncogene. 24(2005) $8252-8258$.

[111] D. Levanon, O. Brenner, V. Negreanu, D. Bettoun, E. Woolf, R. Eilam, J. Lotem , U. Gat, F. Otto, N. Speck, Y. Groner, Spatial and temporal expression pattern of Runx3 (Aml2) and Runx1 (Aml1) indicates non-redundant functions during mouse embryogenesis. Mech. Dev. 109(2001) 413-417.

[112] K. Ito, K.I. Inoue, S.C. Bae, Y. Ito, Runx3 expression in gastrointestinal tract epithelium: resolving the controversy. Oncogene. 28(2009) 1379-1384.

[113] I.H. McKillop, D.M. Moran, X. Jin, L.G. Koniaris, Molecular pathogenesis of hepatocellular carcinoma. J. Surg. Res. 136(2006) 125-135.

[114] Z. Peng, H. Tang, X.Wang, C. Zhou, J. Fan, L. Wang, Z. Jia, Q. Li, X. Le, D. Wei, K. Xie, Inhibition of the growth and metastasis of human colon cancer by restoration of RUNX3 expression in cancer cells. Int. J. Oncol. 33(2008) 979-984.

[115] Z. Zhang, S. Wang, M. Wang, N. Tong, G. Fu, Z. Zhang, Genetic variants in RUNX3 and risk of bladder cancer: a haplotype-based analysis. Carcinogenesis. 29(2008) 1973-1978.

[116] P.I. Hsu, H.L. Hsieh, J. Lee, L.F. Lin, H.C. Chen, P.J. Lu, M. Hsiao, Loss of RUNX3 expression correlates with differentiation, nodal metastasis, and poor prognosis of gastric cancer. Ann. Surg. Oncol. 6 (2009) 1686-1694.

[117] D. Wu, Y. Tian, W. Gong, H. Zhu, Z. Zhang, M. Wang, S. Wang, M.Tan, H.Wu, Z, Zhang. Genetic variants in the Runt-related transcription factor 3 gene contribute to gastric cancer risk in a Chinese population. Cancer Sci. 2009 May 28. 
[118] R.J. Davies, R. Miller, N. Coleman, Colorectal cancer screening: prospects for molecular stool analysis. Nat. Rev. Cancer. 5(2005)199-209.

[119] Y. Jung, J. Park, T.Y. Kim, J.H. Park, H.S. Jong, S.A. Im, K.D. Robertson, Y.J. Bang, T.Y. Kim, Potential advantages of DNA methyltransferase 1 (DNMT1)-targeted inhibition for cancer therapy. J. Mol. Med. 85(2007) 1137-1148.

[120] H.G. Linhart, H. Lin, Y. Yamada, E. Moran, E.J. Steine, S. Gokhale, G. Lo, E. Cantu, M. Ehrich, T. He, A. Meissner, R. Jaenisch, Dnmt3b promotes tumorigenesis in vivo by gene-specific de novo methylation and transcriptional silencing. Genes. Dev. 21(2007) 3110-3122.

[121] C. Huang, H. Ida, K. Ito, H. Zhang, Y. Ito, Contribution of reactivated RUNX3 to inhibition of gastric cancer cell growth following suberoylanilide hydroxamic acid (vorinostat) treatment. Biochem. Pharmacol. 73(2007) 990-1000.

[122] C. Guo, J. Ding, L. Yao, L. Sun, T. Lin, Y. Song, L. Sun, D. Fan, Tumor suppressor gene Runx3 sensitizes gastric cancer cells to chemotherapeutic drugs by downregulating Bcl-2, MDR-1 and MRP-1. Int. J. Cancer. 116(2005) 155-160.

[123] X. Li, Y. Zhang, Y. Zhang, T. Qiao, K. Wu, J. Ding, J. Liu, D. Fan, RUNX3 inhibits growth of HCC cells and HCC xenografts in mice in combination with adriamycin. Cancer. Biol. Ther. 7(2008) 669-676.

[124] S. Kang, J.W. Kim, G.H. Kang, N.H. Park, Y.S. Song, S.B. Kang, H.P. Lee, Polymorphism in folate- and methionine-metabolizing enzyme and aberrant $\mathrm{CpG}$ island hypermethylation in uterine cervical cancer. Gynecol. Oncol. 96(2005)173-180.

[125] K. Blyth, E.R. Cameron, J.C. Neil, The RUNX genes: gain or loss of function in cancer. Nat. Rev. Cancer. 5(2005) 376- 387.

[126] A.M. Arias. Epithelial mesenchymal interactions in cancer and development. Cell 105(2001) 425-431. 


\section{Review criteria}

Information for this Review was compiled by searching the PubMed database for articles published until May 2009. Only articles published in English were considered. Search terms included "RUNX3" and "cancer", in association with the terms "gastric", "colorectal", hepato biliary", "prostate", "esophageal", "urinary bladder", "lung”, ”ovary", “testicular", “cerebral”, "prognosis", "progression”, “carcinogenesis", "survival", "biomarker", "clinicopathology" and "chemotherapy". Full articles were retrieved, and further information was obtained from relevant references. We focused on relevant primary literature rather than review papers to compile this review. In cases where multiple references supported an individual statement, the most recent reference was cited. A specific emphasis was placed on literature focusing on molecular mechanisms and frequency of $R U N X 3$ hypermethylation and protein expression in solid tumor and cancer types in human. 


\section{Figure 1. RUNX3 transactivation in gastric carcinogenesis.}

Downstream of transforming growth factor (TGF)- $\beta$ signalling, RUNX3 transactivates target genes synergistically with Smads and P300. RUNX3 positively regulates the expression of Bim and p21, and negatively regulates $V E G F$, and thereby affects apoptosis, cell growth arrest, and angiogenesis, respectively. $\mathrm{CBF} \beta / \mathrm{PEBP} 2 \beta$ is a non-DNA-binding partner of RUNX, and confers high DNA-binding affinity and stability to RUNX. FoxO3a interacts with RUNX3 to activate Bim and Ku70, a DNA repair-related protein that inhibits transactivation of RUNX3. EZH2 downregulates $R U N X 3$ expression by increasing histone $\mathrm{H} 3$ methylation on the $R U N X 3$ promoter.

Figure 2. Mislocalization of RUNX3 protein to the cytoplasm represents an alternative mechanism of $R U N X 3$ inactivation in human neoplasms

Representative histopathological images of mislocalized RUNX3 in human cancers. Nuclear localization of RUNX3 in normal tissues of colorectal (A) and gastric (D) epithelium, breast lobules (G), and liver (J). Inset in D indicates strong expression of RUNX3 in the chief cells (black arrow) compared to weak staining in the parietal cells (red arrow). Mislocalization of RUNX3 in the cytoplasm of sporadic colorectal adenomatous polyps (B) and adenocarcinomas (C), intestinal metaplasia (E) and adenocarcinoma (F) in stomach, ductal carcinoma in situ $(\mathrm{H})$ and invasive ductal carcinoma (I) in breast, and hepatocellular carcinomas (K). A to F, original magnification x 1000; $G$ to $K$, original magnification $x$ 400; inset in D, original magnification x 1000 .

Figure 3. RUNX3 attenuates oncogenic $\beta$-catenin/TCFs in intestinal tumorigenesis

(A) A ternary complex between RUNX3 and $\beta$-catenin/TCFs functions as a 'node' downstream of oncogenic signaling of Wnt and tumor suppressive signaling of TGF- $\beta$ /BMPs. The complex formation inhibits upregulation of cyclin D1, EphB2, AXIN2, c-Myc and CD44 by $\beta$-catenin/TCFs, and $p 21$ by RUNX3. TLE6D, a transcriptional co-regulator, directly antagonizes RUNX3 transactivation. RUNX3 is repressed via promoter hypermethylation by EZH2, and most likely also by DNMT3b. 
(B) Inactivation of either $R U N X 3$ or $A P C$ can induce colonic adenomas in mice and humans. $R u n \times 3^{+/-}$and $A p c^{\mathrm{Min} /+} \mathrm{BALB} / \mathrm{c}$ mice develop the same number and size of small intestinal adenomas. Small adenomas (initiation of adenoma formation) in the $R u n x 3^{+/} A p c^{\mathrm{Min} /+}$ double compound mice have either downregulated Runx3 expression or nuclear $\beta$-catenin accumulation, but never both, indicating that biallelic inactivation of either Runx3 or Apc is sufficient for adenoma induction. This feature is consistent with human adenomatous polyp cases. In contrast, $\operatorname{Run} x 3^{+/-} A p c^{\mathrm{Min} /+}$ double compound mice develop adenomas in the small and large intestines, and adenocarcinomas in the small intestine. Large adenomas and adenocarcinomas of both mice and humans displayed aberrant nuclear/cytoplasmic $\beta$-catenin accumulation, and reduced RUNX3 expression, which suggests that alteration of both genes causes strong Wnt activation. Thus, inactivation of both $R U N X 3$ and $A P C$ is necessary for the progression of adenomas to adenocarcinomas.

\section{Figure 4. RUNX3 inactivation is an early molecular event in colonic and breast carcinogenesis}

In colon cancers, the familial adenomatous polyposis (FAP) and sporadic traditional adenomas (sTA) develop according to the traditional adenoma-carcinoma sequence (AD-CA), whereas the serrated polyps, such as hyperplastic polyps (HP) and traditional serrated adenomas (TSA), follow the serrated-polyp neoplasia pathway, with increasing DNA hypermethylation. FAP showed frequent RUNX3 inactivation by promoter hypermethylation in the aberrant crypt foci (ACF), the earliest dysplastic lesion formation. sTA had levels of RUNX3 inactivation that were comparable to those in small (SmAd) and large adenomas (LAd) of FAP. In contrast, RUNX3 inactivation was more frequently accompanied by promoter hypermethylation in HPs and TSAs, than in sTAs, which is consistent with the hypothesis that increasing and progressive DNA methylation is an early molecular event in the evolution of serrated colorectal polyps. The status of RUNX3 in serrated adenocarcinomas is still unknown. In breast cancers, RUNX3 inactivation by frequent promoter hypermethylation and protein mislocalization is often detected in ductal carcinoma in situ (DCIS) and invasive ductal carcinoma (IDC), suggesting that the promoter hypermethylation and the protein mislocalization are early events in breast cancer progression. $R U N X 3$ methylation is more frequent in estrogen-exposed progenitor cells than in the non-estrogen-exposed control cells. This suggests a possible link between estrogen injury of breast stem/progenitor cells and carcinogenesis, through 
estrogen-induced epigenetic changes. 
Table 1 RUNX3 inactivation in human cancers

A. In Cancers

\begin{tabular}{|c|c|c|c|c|c|c|}
\hline \multirow[b]{2}{*}{ Cancer Site } & \multirow[b]{2}{*}{ Histological Subtype } & \multicolumn{2}{|c|}{ RUNX3 Methylation } & \multicolumn{2}{|c|}{ Reduced RUNX3 Expression } & \multirow[b]{2}{*}{ Reference } \\
\hline & & $\begin{array}{l}\text { Percentage } \\
\text { (\%) }\end{array}$ & $\begin{array}{l}\text { Total no. of } \\
\text { cases }(n)\end{array}$ & $\begin{array}{l}\text { Percentage } \\
\text { (\%) }\end{array}$ & $\begin{array}{l}\text { Total no. of } \\
\text { cases (n) }\end{array}$ & \\
\hline \multirow[t]{3}{*}{ Esophageal } & EAC & 48 & 77 & 38 & 21 (PCR) & [12] \\
\hline & ESCC & $\begin{array}{c}70 \\
100\end{array}$ & $\begin{array}{c}51 \\
4(\mathrm{CL})\end{array}$ & 68 & $62(\mathrm{IHC})$ & [69] \\
\hline & EAC & 73 & 37 & & & [71] \\
\hline \multirow[t]{13}{*}{ Gastric } & $A C$ & & & 56 & $102(\mathrm{IHC})$ & {$[100]$} \\
\hline & & & & 39 & $95(1 \mathrm{HC})$ & [116] \\
\hline & & & & 83 & $97(\mathrm{IHC})$ & [101] \\
\hline & & 53 & 57 & & & [54] \\
\hline & & 55 & 40 & & & [99] \\
\hline & & & & 49 & $120(\mathrm{IHC})$ & [37] \\
\hline & & & & 44 & $97(\mathrm{IHC})$ & [13] \\
\hline & & & & 30 & $86(\mathrm{IHC})$ & [104] \\
\hline & & 64 & 22 & $75-86$ & 89 (PCR, ISH) & [56] \\
\hline & & $\begin{array}{l}71 \\
43\end{array}$ & $\begin{array}{c}80 \\
7(\mathrm{CL})\end{array}$ & & & [98] \\
\hline & & $\begin{array}{l}64 \\
60\end{array}$ & $\begin{array}{c}75 \\
5(\mathrm{CL})\end{array}$ & & & [15] \\
\hline & & $\begin{array}{l}45 \\
70\end{array}$ & $\begin{array}{c}93 \\
10(C L)\end{array}$ & 20 & $5(\mathrm{CL})(\mathrm{PCR})$ & [55] \\
\hline & & 100 & 3 & & & [8] \\
\hline \multirow[t]{9}{*}{ Colorectal } & $A C$ & $\begin{array}{l}75 \\
18\end{array}$ & $\begin{array}{c}16(\mathrm{CL}) \\
87\end{array}$ & 50 & $32(\mathrm{CL})(\mathrm{PCR})$ & {$[107]$} \\
\hline & & $\begin{array}{l}21 \\
65\end{array}$ & $\begin{array}{c}91 \\
17(\mathrm{CL})\end{array}$ & 65 & $17(\mathrm{CL})(\mathrm{PCR})$ & [14] \\
\hline & & 5 & 61 & & & [15] \\
\hline & & 34 & 92 & & & [102] \\
\hline & & 20 & 30 & & & [105] \\
\hline & & 20 & 920 & & & [108] \\
\hline & & 33 & 45 & 29 & $48(\mathrm{IHC})$ & [32] \\
\hline & & & & $\begin{array}{l}36 \\
29\end{array}$ & $\begin{array}{l}14 \text { (PCR) } \\
83 \text { (IHC) }\end{array}$ & [114] \\
\hline & & & & 26 & $849(\mathrm{IHC})$ & [106] \\
\hline \multirow[t]{8}{*}{ Hepatic } & $\mathrm{HCC}$ & 48 & 62 & & & [77] \\
\hline & & 73 & 48 & & & [15] \\
\hline & & $\begin{array}{l}46 \\
80\end{array}$ & $\begin{array}{c}41 \\
5(\mathrm{CL})\end{array}$ & $\begin{array}{l}51 \\
80\end{array}$ & $\begin{array}{c}41 \text { (PCR) } \\
5 \text { (CL) }\end{array}$ & [72] \\
\hline & & $\begin{array}{l}41 \\
40\end{array}$ & $\begin{array}{c}73 \\
10(C L)\end{array}$ & & & [73] \\
\hline & & 48 & 19 & & & [74] \\
\hline & & 69 & $62^{*}$ & & & [75] \\
\hline & & $\begin{array}{l}36 \\
45 \\
21 \\
29\end{array}$ & $\begin{array}{c}44 \text { (All) } \\
20 \text { (WDHCC) } \\
28 \text { (SmHCC) } \\
35 \text { (Early } \\
\text { HCC) }\end{array}$ & & & [76] \\
\hline & & 50 & 6 & 62 & $34(\mathrm{IHC})$ & Unpublished \\
\hline \multirow[t]{2}{*}{ Gallbladder } & $A C$ & 32 & 50 & & & [16] \\
\hline & & 22 & 9 & & & [17] \\
\hline Bile duct & $A C$ & 78 & 23 & & & [17] \\
\hline
\end{tabular}




\begin{tabular}{|c|c|c|c|c|c|c|}
\hline & & 70 & $10(\mathrm{CL})$ & 70 & $10(\mathrm{CL})(\mathrm{PCR})$ & [18] \\
\hline $\begin{array}{l}\text { Duodenal } \\
\text { Ampullary }\end{array}$ & $A C$ & 20 & 5 & & & {$[17]$} \\
\hline \multirow[t]{3}{*}{ Pancreas } & $A C$ & 75 & $12(\mathrm{CL})$ & 75 & $12(\mathrm{CL})(\mathrm{PCR})$ & [18] \\
\hline & & & & $\begin{array}{l}71 \\
75\end{array}$ & $\begin{array}{c}24(\mathrm{IHC}) \\
8(\mathrm{CL})\end{array}$ & [78] \\
\hline & & 63 & 32 & & & [79] \\
\hline \multirow[t]{5}{*}{ Bladder } & TCC & $\begin{array}{l}73 \\
86\end{array}$ & $\begin{array}{c}124 \\
7(\mathrm{CL})\end{array}$ & & & [80] \\
\hline & & 42 & 57 & & & [27] \\
\hline & & 71 & 118 & & & [81] \\
\hline & & 39 & 304 & & & [82] \\
\hline & & $\begin{array}{l}53 \\
33 \\
66\end{array}$ & $\begin{array}{c}15 \\
43 \text { (Urine) } \\
3\end{array}$ & & & [83] \\
\hline \multirow[t]{7}{*}{ Breast } & IDC & 25 & 25 & & & [15] \\
\hline & & 22 & 37 & & & [27] \\
\hline & & $\begin{array}{l}52 \\
47\end{array}$ & $\begin{array}{c}44 \\
19(\mathrm{CL})\end{array}$ & $\begin{array}{c}100 \\
43\end{array}$ & $\begin{array}{c}44(\mathrm{IHC}) \\
19(\mathrm{CL})\end{array}$ & [20] \\
\hline & & & & 88 & $96(\mathrm{IHC})$ & [63] \\
\hline & & $\begin{array}{l}53 \\
57\end{array}$ & $\begin{array}{c}19 \\
13(\mathrm{CL})\end{array}$ & $\begin{array}{l}85 \\
67\end{array}$ & $\begin{array}{l}20 \text { (PCR) } \\
13 \text { (CL) }\end{array}$ & [64] \\
\hline & & 87 & 15 & 65 & $88(\mathrm{IHC})$ & [66] \\
\hline & & 76 & 21 & 91 & $23(\mathrm{IHC})$ & [30] \\
\hline \multirow[t]{4}{*}{ Prostate } & $A C$ & 32 & 37 & & & [21] \\
\hline & & 23 & 44 & & & [15] \\
\hline & & 10 & 50 & & & [27] \\
\hline & & 16 & 179 & & & [84] \\
\hline Ovary & GCT & $\begin{array}{l}56 \\
33\end{array}$ & $\begin{array}{c}25 \\
6(\mathrm{CL})\end{array}$ & 33 & $6(\mathrm{CL})(\mathrm{PCR})$ & [22] \\
\hline \multirow[t]{2}{*}{ Testis } & $\begin{array}{l}\text { YST (infantile) } \\
\text { GCT }\end{array}$ & $\begin{array}{c}80 \\
0\end{array}$ & $\begin{array}{l}10 \\
12\end{array}$ & & & [24] \\
\hline & GCT & 2 & 55 & & & [85] \\
\hline \multirow[t]{3}{*}{$\begin{array}{l}\text { Uterus and } \\
\text { adnexa }\end{array}$} & Endometrial AC & 86 & 21 & $\begin{array}{c}57 \\
100\end{array}$ & $\begin{array}{c}21 \text { (IHC) } \\
3(\mathrm{CL})(\mathrm{PCR})\end{array}$ & [25] \\
\hline & $\begin{array}{c}\text { Endometrial AC } \\
\text { AC cervix }\end{array}$ & $\begin{array}{c}13 \\
3\end{array}$ & $\begin{array}{l}24 \\
40\end{array}$ & & & [15] \\
\hline & SCC cervix & 2 & 82 & & & [124] \\
\hline \multirow[t]{6}{*}{ Lung } & $\begin{array}{c}\text { Total NSCLC } \\
\text { ADC } \\
\text { SCC } \\
\text { LCC + ADSCC }\end{array}$ & $\begin{array}{c}20 \\
28 \\
7 \\
33\end{array}$ & $\begin{array}{c}75 \\
43 \\
29 \\
3\end{array}$ & & & [26] \\
\hline & Unknown & 46 & 24 & & & [15] \\
\hline & $\begin{array}{c}\text { Total NSCLC } \\
\text { ADC } \\
\text { SCC } \\
\text { LCC } \\
\text { SCLC } \\
\text { Carcinoid } \\
\text { Malignant } \\
\text { mesothelioma }\end{array}$ & $\begin{array}{c}21 \\
22 \\
16 \\
67 \\
0 \\
0 \\
33\end{array}$ & $\begin{array}{c}117 \\
60 \\
51 \\
6 \\
5 \\
18 \\
63\end{array}$ & & & [27] \\
\hline & $\begin{array}{c}\text { Total NSCLC } \\
\text { ADC } \\
\text { SCC } \\
\text { LCC } \\
\text { NSCLC }\end{array}$ & $\begin{array}{l}24 \\
27 \\
18 \\
33 \\
50\end{array}$ & $\begin{array}{c}25 \\
11 \\
11 \\
3 \\
6(\mathrm{CL})\end{array}$ & 19 & $31(\mathrm{CL})$ & [87] \\
\hline & $A D C$ & & & 48 & $98(\mathrm{IHC})$ & [89] \\
\hline & $\begin{array}{c}\text { Total NSCLC } \\
\text { ADC }\end{array}$ & $\begin{array}{l}25 \\
36\end{array}$ & $\begin{array}{c}120 \\
72\end{array}$ & & & [86] \\
\hline
\end{tabular}




\begin{tabular}{|c|c|c|c|c|c|c|}
\hline & $\begin{array}{c}\text { LCC } \\
\text { SCC } \\
\text { ADSCC }\end{array}$ & $\begin{array}{c}50 \\
7 \\
0\end{array}$ & $\begin{array}{c}2 \\
45 \\
1\end{array}$ & & & \\
\hline & $\begin{array}{c}\text { Total NSCLC } \\
\text { ADC } \\
\text { LCC } \\
\text { SCC } \\
\text { SCLC }\end{array}$ & $\begin{array}{c}4 \\
44 \\
25 \\
0 \\
5\end{array}$ & $\begin{array}{c}23(\mathrm{CL}) \\
16(\mathrm{CL}) \\
4(\mathrm{CL}) \\
3(\mathrm{CL}) \\
20(\mathrm{CL})\end{array}$ & $\begin{array}{l}48 \\
50 \\
25 \\
33 \\
50\end{array}$ & $\begin{array}{c}23(\mathrm{CL})(\mathrm{PCR}) \\
16 \\
4 \\
3 \\
20\end{array}$ & \\
\hline & NSCLC & 25 & 101 & & & [90] \\
\hline & NSCLC & 89 & 19 & & & [88] \\
\hline Brain & Glioblastoma & 56 & $32(\mathrm{CL})$ & & & [28] \\
\hline Skin & $\mathrm{BCC}$ & & & 0 & $75(\mathrm{IHC})$ & [34] \\
\hline & $\begin{array}{c}\text { Melanoma } \\
\text { Primary melanoma } \\
\text { Metastatic melanoma }\end{array}$ & $\begin{array}{c}29 \\
4 \\
17\end{array}$ & $\begin{array}{c}17(\mathrm{CL}) \\
52 \\
30\end{array}$ & $\begin{array}{l}100 \\
100 \\
100\end{array}$ & $\begin{array}{c}11(\mathrm{CL})(\mathrm{PCR}) \\
82 \\
41\end{array}$ & [91] \\
\hline Laryngeal & & 62 & 37 & & & [15] \\
\hline Paediatric & $\begin{array}{l}\text { Retinoblastoma } \\
\text { Ewing sarcoma } \\
\text { Hepatoblastoma } \\
\text { Medulloblastoma } \\
\text { Rhabdomyosarcoma } \\
\text { Neuroblastoma } \\
\text { Wilm's tumour } \\
\text { Osteosarcoma }\end{array}$ & $\begin{array}{c}0 \\
0 \\
0 \\
0 \\
0 \\
0 \\
0 \\
50\end{array}$ & $\begin{array}{l}30 \\
7 \\
22 \\
12 \\
17 \\
27 \\
25 \\
10\end{array}$ & & & [27] \\
\hline
\end{tabular}


Table 1 RUNX3 inactivation in human cancers

B. In Precursor Lesions

\begin{tabular}{|c|c|c|c|c|c|c|}
\hline \multirow[b]{2}{*}{ Cancer Site } & \multirow{2}{*}{$\begin{array}{l}\text { Histological } \\
\text { Subtype }\end{array}$} & \multicolumn{2}{|c|}{ RUNX3 Methylation } & \multicolumn{2}{|c|}{ Reduced RUNX3 Expression } & \multirow[b]{2}{*}{ Reference } \\
\hline & & $\begin{array}{l}\text { Percentage } \\
\text { (\%) }\end{array}$ & $\begin{array}{l}\text { Total no. of } \\
\text { cases (n) }\end{array}$ & Percentage (\%) & $\begin{array}{l}\text { Total no. of } \\
\text { cases }(n)\end{array}$ & \\
\hline Esophagus & $\begin{array}{l}\text { BE } \\
\text { LGD } \\
\text { HGD }\end{array}$ & $\begin{array}{l}25 \\
57 \\
67\end{array}$ & $\begin{array}{c}93 \\
14 \\
6\end{array}$ & & & [12] \\
\hline Lung & $\begin{array}{l}\text { LGD-AAH } \\
\text { HGD-AAH }\end{array}$ & $\begin{array}{l}28 \\
71\end{array}$ & $\begin{array}{l}32 \\
24\end{array}$ & & & [88] \\
\hline \multirow[t]{2}{*}{ Prostate } & PIN & 14 & 14 & & & [21] \\
\hline & $\mathrm{BPH}$ & 0 & 30 & & & {$[84]$} \\
\hline Stomach & $\begin{array}{c}\text { Chronic gastritis } \\
\text { IM } \\
\text { Adenoma }\end{array}$ & $\begin{array}{c}8 \\
28 \\
27\end{array}$ & $\begin{array}{l}99 \\
32 \\
77\end{array}$ & & & {$[15]$} \\
\hline \multirow[t]{3}{*}{ Hepatic } & Chronic hepatitis B & 0 & 40 & & & [15] \\
\hline & $\begin{array}{c}\text { CAH } \\
\text { CPH } \\
\text { Cirrhosis }\end{array}$ & $\begin{array}{l}33 \\
33 \\
42\end{array}$ & $\begin{array}{c}6 \\
3 \\
61\end{array}$ & & & [73] \\
\hline & $\mathrm{HCV}+\mathrm{NL}-\mathrm{HCC}$ & 24 & 46 & & & [75] \\
\hline Gallbladder & Chronic cholecystitis & 0 & 25 & & & {$[16]$} \\
\hline \multirow[t]{2}{*}{ Colon } & sTA & 48 & 35 & 29 & $35(\mathrm{IHC})$ & [32] \\
\hline & $\begin{array}{c}\text { Sporadic Polyps } \\
\text { sTA } \\
\text { HP } \\
\text { TSA } \\
\text { FAP Polyps } \\
\text { ACF } \\
\text { SmAd } \\
\text { LAd }\end{array}$ & $\begin{array}{l}73 \\
44 \\
89 \\
86 \\
74 \\
80 \\
72 \\
60\end{array}$ & $\begin{array}{l}49 \\
16 \\
19 \\
14 \\
38 \\
15 \\
18 \\
5\end{array}$ & $\begin{array}{l}52 \\
18 \\
79 \\
57 \\
76 \\
86 \\
62 \\
46\end{array}$ & $\begin{array}{c}50(\mathrm{IHC}) \\
17 \\
19 \\
14 \\
144(\mathrm{IHC}) \\
91 \\
40 \\
13\end{array}$ & {$[31]$} \\
\hline Breast & DCIS & 75 & 40 & 88 & 40 (IHC) & [30] \\
\hline
\end{tabular}

NSCLC, non small cell lung cancer; ADC, Adenocarcinoma of lung; SCC, squamous cell carcinoma of lung; ADSC. Adenosquamous lung carcinoma; SCLC, small cell lung carcinoma of lung; LC, large cell carcinoma of lung; IHC, immunohistochemistry; PCR, polymerase chain reaction; CL, cell line; NB, northern blot; ISH, in situ hybridization; EAC, esophageal adenocarcinoma; ESCC, esophageal squamous cell carcinoma; AC, adenocarcinoma; HCC, hepatocellular carcinoma; TCC, transitional cell carcinoma; IDC, invasive ductal carcinoma; DCIS, ductal carcinoma in situ; GCT, granulosa cell tumor; SEC, serous epithelial carcinoma; YST, yolk sac tumor; BCC, basal cell carcinoma; BE, Barrett's esophagus; LGD, low grade dysplasia; HGD, high-grade dysplasia; IM, intestinal metaplasia; PIN, prostatic intraepithelial neoplasia; STA, sporadic traditional adenoma; HP, hyperplastic polyp; TSA, traditional serrated adenoma; FAP, familial adenomatous polyposis; ACF, aberrant crypt foci; SmAD, small adenoma; LAd, large adenoma; AAH, atypical adenomatous hyperplasia; *, indicates 62 total HCCs (44 HCV+ and 18 HCV-); BPH, benign prostate hypertrophy; ADSCC, adenosquamous cell carcinoma; HCV+NL-HCC, HCV positive non neoplastic liver tissue from HCC patients; WDHCC, welldifferentiated hepatic cellular carcinoma; SmHCC, small HCC (less than $3 \mathrm{~cm}$ ); CAH, chronic active hepatitis; $\mathrm{CPH}$, chronic persistent hepatitis 
Table 2 Clinical and morphomolecular associations of RUNX3 in human cancers

\begin{tabular}{|c|c|c|c|c|}
\hline Tumor type & Assay & Patient cohort & Association & Reference \\
\hline \multirow[t]{4}{*}{ Gastric } & $\mathrm{IHC}$ & GC, surgically treated, $n=102$ & RUNX3 expression associated with chief cell phenotype in normal and malignant gastric mucosa & [100] \\
\hline & $\mathrm{IHC}$ & GC, surgically treated, $n=95$ & $\begin{array}{l}\text { Loss of RUNX3 expression was more frequent in diffuse and mixed type cancer than intestinal } \\
\text { type cancer }\end{array}$ & [116] \\
\hline & MSP & GC, surgically treated, $n=80$ & RUNX3 promoter methylation is significantly higher in intestinal compared to diffuse type cancers & [98] \\
\hline & $\begin{array}{l}\text { MSP/MSI/mtMSI } \\
\text { analysis }\end{array}$ & GC, surgically treated, $n=100$ & Significant RUNX3 methylation seen in nMSI and mtMSI GCs compared to MSS and mtMSS GCs & [99] \\
\hline \multirow[t]{3}{*}{ Colonic } & MSP & Sporadic CRC, surgically treated, $n=92$ & RUNX3 methylation associated with poorly differentiated adenocarcinomas & [102] \\
\hline & MSP & Sporadic CRC, surgically treated, $n=91$ & RUNX3 hypermethylation was common in tumors with high frequency of $\mathrm{MSI}-\mathrm{H}$ status & [14] \\
\hline & PCR /MethyLight & MSI-H sporadic CRC, $\mathrm{n}=144$ & $\begin{array}{l}\text { TGFBR2 mutation is positively correlated directly with CIMP-high and indirectly with RUNX3 } \\
\text { methylation }\end{array}$ & [103] \\
\hline \multirow[t]{4}{*}{$\begin{array}{l}\text { Hepatobiliary } \\
\text { and Pancreas }\end{array}$} & MSP & HCC, surgically treated, $n=41$ & RUNX3 methylation correlated positively with $\mathrm{HCV}$ positive status and capsule formation in $\mathrm{HCCs}$ & [72] \\
\hline & $\mathrm{IHC}$ & HCC, surgically treated, $n=34$ & Nuclear RUNX3 expression correlated with alchoholism & Unpublished \\
\hline & COBRA & $\begin{array}{l}\text { Total: } 176 \text { liver tissues ( } 77 \text { HCCs and matched non- } \\
\text { cancerous liver tissues) and } 22 \text { normal liver tissues }\end{array}$ & $\begin{array}{l}\text { RUNX3 methylation frequently associated with HCV positve liver tissues compared to virus- } \\
\text { negative livers }\end{array}$ & [75] \\
\hline & MSP & $\begin{array}{l}\text { Biliary tract (BDCa, } n=23 ; G B C a, n=9 \text { and } A M P C a \\
n=5)\end{array}$ & $\begin{array}{l}\text { Patients of biliary tract tumors with methylated RUNX3 promoter were significantly older than } \\
\text { those with unmethylated RUNX3 promoter }\end{array}$ & [17] \\
\hline \multirow[t]{3}{*}{ Esophageal } & qRT-MSP & $E A C, n=37, B E, n=47$ & RUNX3 methylation significantly higher in EAC than BE & [71] \\
\hline & $\mathrm{IHC}$ & ESCC,surgically treated, $n=144$ & $\begin{array}{l}\text { RUNX3 expression higher in well differentiated ESCCs compared to moderately and poorly } \\
\text { differentiated variants }\end{array}$ & [70] \\
\hline & qRT-MSP & $\begin{array}{l}\text { Endoscopic biopsy samples of } E A C, n=77, B E \\
n=93, N E, n=64\end{array}$ & RUNX3 hypermethylation is an independent risk factor for progression of BE to HGD or EAC & [12] \\
\hline \multirow[t]{2}{*}{ Lung } & MSP & NSCLC, surgically treated, $n=120$ & $\begin{array}{l}\text { RUNX3 methylation was more frequent in females than males, non-smokers than smokers, well } \\
\text { differentiated compared to moderetly or poorly differentiated tumors, ADC than in SCC) and in } \\
\text { non-vascularly invasive tumors }\end{array}$ & [86] \\
\hline & $\mathrm{IHC}$ & $A D C$, surgically treated, $n=98$ & $\begin{array}{l}\text { Positive RUNX3 expression frequently seen in ADC with bronchioalveoloar component than those } \\
\text { without, decreased RUNX3 expression correlated with poor differentiation }\end{array}$ & [89] \\
\hline \multirow[t]{2}{*}{ Breast } & MSP and IHC & $\begin{array}{l}\text { Breast cancer (histology unknown), surgically } \\
\text { treated, } n=37\end{array}$ & RUNX3 methylation correlated significantly with positive ER expression & [27] \\
\hline & MSP and IHC & IDC, surgically treated, $n=23$ & RUNX3 methylation correlated with both positive ER and PR expression & [30] \\
\hline \multirow[t]{2}{*}{$\begin{array}{l}\text { Urinary } \\
\text { bladder }\end{array}$} & qRT-MSP & TCCs, surgically treated, $n=304$ & $\begin{array}{l}\text { RUNX3 methylation increases with age in smokers. TCCs from smokers are older than those from } \\
\text { non-smokers }\end{array}$ & [82] \\
\hline & MSP & TCCs, surgically treated, $n=57$ & RUNX3 methylation was associated with tumors with invasion of muscularis propria & [27] \\
\hline
\end{tabular}


Table 3 Prognostic association of RUNX3

\begin{tabular}{|c|c|c|c|c|}
\hline Tumor type & Assay & Patient cohort & Association & Reference \\
\hline \multirow[t]{3}{*}{ Gastric } & $\mathrm{IHC}$ & $\mathrm{GC}$, surgically treated, $\mathrm{n}=86$ & $\begin{array}{l}\text { Positve RUNX3 expression predicted longer overall survival, while loss or weak expression was associated } \\
\text { with poor survival }\end{array}$ & [104] \\
\hline & $\mathrm{IHC}$ & GC, surgically treated, $\mathrm{n}=95$ & Loss of RUNX3 expression correlated with lymph node metastasis and poor survival & [116] \\
\hline & $\mathrm{IHC}$ & GC, surgically treated, $n=97$ & Loss of RUNX3 expression was associated with poor clinical outcome & [101] \\
\hline \multirow[t]{2}{*}{ Colonic } & MethyLight & MSS metastatic CRC, $\mathrm{n}=30$ & $\begin{array}{l}\text { RUNX3 methylation as a part of CIMP-high panel was associated with poor survival in MSS metastatic } \\
\text { CRCs }\end{array}$ & [105] \\
\hline & IHC & $\begin{array}{l}\text { Sporadic CRC, surgically treated, (Stages I-IV), } \\
\mathrm{n}=849\end{array}$ & $\begin{array}{l}\text { Loss of nuclear RUNX3 expression and increasing cytoplasmic accumulation of RUNX3 (inactive RUNX3) } \\
\text { observed in advanced stages }\end{array}$ & [106] \\
\hline \multirow[t]{2}{*}{$\begin{array}{l}\text { Hepatobiliary } \\
\text { and Pancreas }\end{array}$} & RT-PCR & HCC, surgically treated, $n=41$ & $\begin{array}{l}\text { Decreased RUNX3 expression was associated with advanced stage of disease and loss of } \\
\text { heterozygosity-detected cases }\end{array}$ & [72] \\
\hline & MSP & $A D C$ of pancreas surgically treated, $n=32$ & RUNX3 hypermethylation was associated with worse prognosis & [79] \\
\hline \multirow[t]{3}{*}{ Esophageal } & RT-PCR/ISH & ESCC, surgically treated, $n=61$ & $\begin{array}{l}\text { Loss of RUNX3 expression was correlated to worse survival. In early (T1/T2) tumors, prevalence of lymph } \\
\text { vessel invasion and positive lymph nodes were significantly higher in RUNX3-negative tumors }\end{array}$ & [68] \\
\hline & IHC/MSP & $\begin{array}{l}\text { ESCC, } n=62 \text {, preradiotherapy (endoscopic biopsy) } \\
\text { and post-radiotherapy (resection) samples }\end{array}$ & $\begin{array}{l}\text { Nuclear RUNX3 expression was associated with better radiosensitivity and prognosis while } \\
\text { cytoplasmic/negative RUNX3 was correlated to radioresistance and poor prognosis }\end{array}$ & [69] \\
\hline & IHC & ESCC,surgically treated, $n=66$ & $\begin{array}{l}\text { 3yr survival rate was lower in patients with decreased RUNX3 expression than those with positive } \\
\text { expression }\end{array}$ & [70] \\
\hline \multirow[t]{3}{*}{ Lung } & MSP & NSCLC, surgically treated, $n=101$ & RUNX3 methylation was correlated to shorter survival for all stages as well as for ADC & [90] \\
\hline & MSP & NSCLC, surgically treated, $n=25$ & RUNX3 methylation was more prevalent in advanced lung cancer (stage III) & [87] \\
\hline & $\mathrm{IHC}$ & ADC, surgically treated, $n=98$ & $\begin{array}{l}\text { Five year survival rate was higher in patients with positive RUNX3 expression compared to decreased } \\
\text { expression }\end{array}$ & [89] \\
\hline \multirow[t]{2}{*}{$\begin{array}{l}\text { Urinary } \\
\text { Bladder }\end{array}$} & $\begin{array}{l}\text { MSP/ } \\
\text { sequencing }\end{array}$ & $\begin{array}{l}\text { TCCs, surgically treated transurethral biopsies, } \\
\mathrm{n}=118\end{array}$ & $\begin{array}{l}\text { RUNX3 methylation was correlated to muscle invasion, tumor progression and overall and cancer-specific } \\
\text { survival }\end{array}$ & [81] \\
\hline & MSP & TCCs, surgically treated, $n=124$ & $\begin{array}{l}\text { RUNX3 methylation was associated with } 100 \text { fold risk of bladder cancer, tumor stage and recurrence. } \\
\text { RUNX3 methylation was more frequent in invasive compared to superficial tumors }\end{array}$ & [80] \\
\hline \multirow[t]{2}{*}{ Prostate } & MSP & PCA, surgically treated, $n=50$ & RUNX3 methylation was associated with poorer disease-free prognosis & [27] \\
\hline & MSP & PCA, surgically treated, $n=37$ & RUNX3 methylation was associated with cancers with high serum PSA and high Gleason score & [21] \\
\hline Breast & IHC & IDC, surgically treated, $n=88$ & $\begin{array}{l}\text { Positive RUNX3 expression was correlated to clinical stage, lymphnode metastasis and ER and PR } \\
\text { expression. Loss of RUNX3 was associated with poor survival }\end{array}$ & [66] \\
\hline $\begin{array}{l}\text { Oral, salivary } \\
\text { gland and } \\
\text { head and } \\
\text { neck cancers }\end{array}$ & $\mathrm{IHC}$ & $\begin{array}{l}\text { Oral SCC }(n=85) \\
\text { ACC of salivary gland }(n=73) \\
\text { HNSCC }(n=52)\end{array}$ & $\begin{array}{l}\text { Low RUNX3 expression was correlated to poor survival in oral SCCs } \\
\text { Loss of RUNX3 was correlated to poor survival and distant metastasis in ACCs of salivary glands } \\
\text { Positive RUNX3 expression correlated with invasive and metastatic tumors }\end{array}$ & {$[95]$} \\
\hline
\end{tabular}

GC, gastric cancer; CRC, colorectal cancer; ESCC, esophageal squamous cell carcinoma; TCC, transitional cell carcinoma;AC, adenocarcinoma; HCC, hepatocellular carcinoma; HCV, hepatitis C virus;

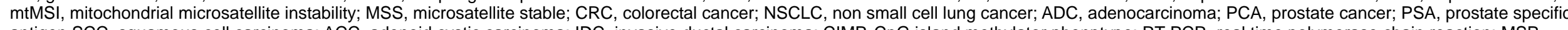
antigen SCC, squamous cell carcinoma; ACC, adenoid cystic carcinoma; IDC, invasive ductal carcinoma; CIMP, CpG island methylator phenptype; RT-PCR, real time polymerase chain reaction; MSP, methylation specific PCR; IHC, immunohistochemistry; ISH, in situ hybridization;ER, estrogen receptor; PR, progesterone receptor 


\section{Figure 1}

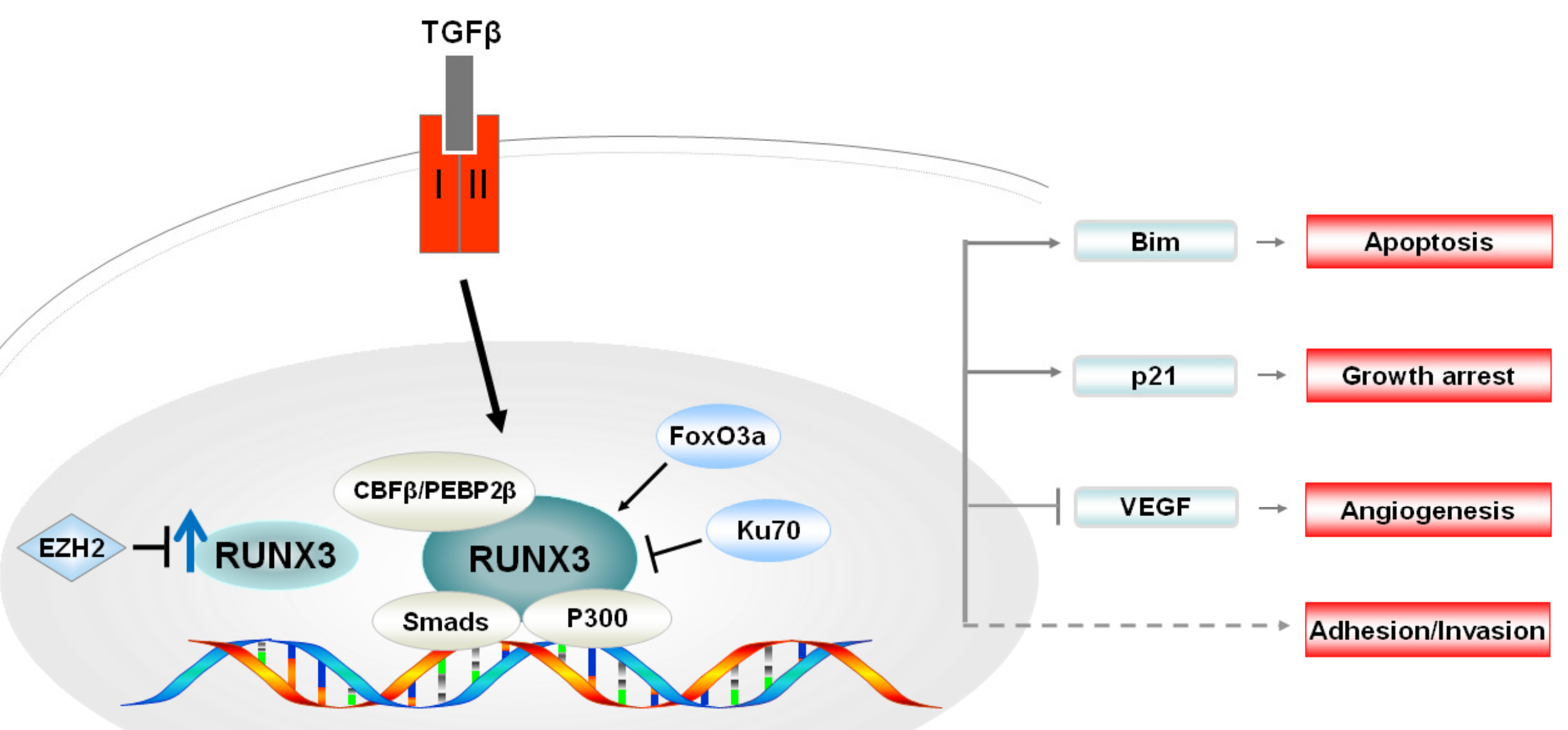


Figure 2
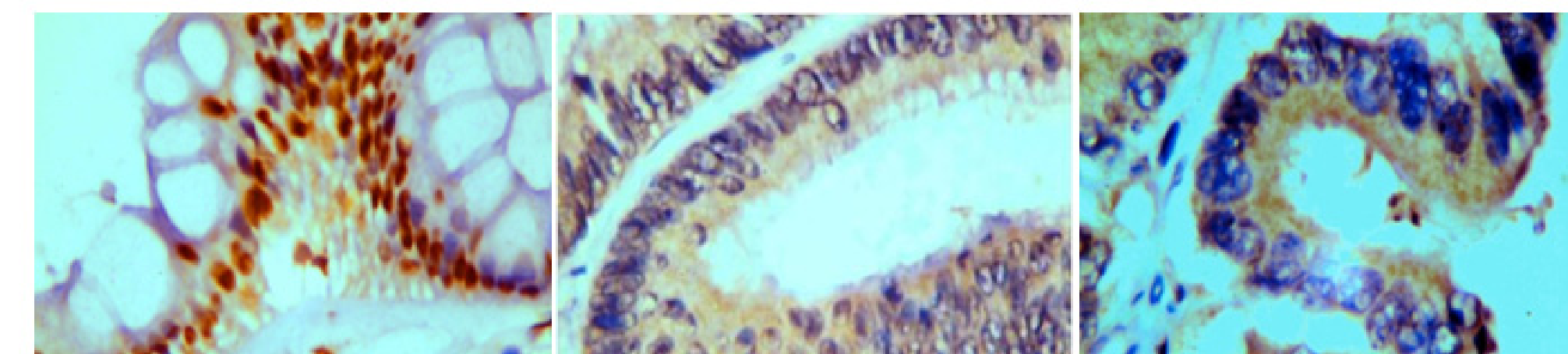

$-1,160+2$

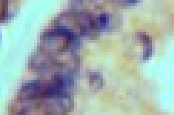

$$
\begin{aligned}
& A \text { : } 3 \text {. } \\
& \text { B / s C }
\end{aligned}
$$

-

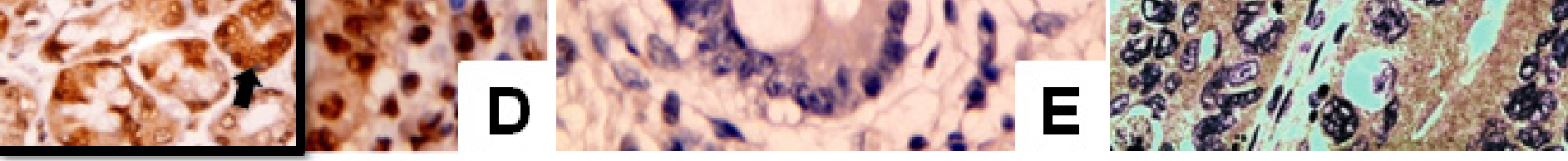

8)

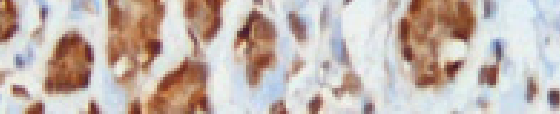

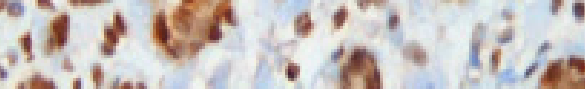

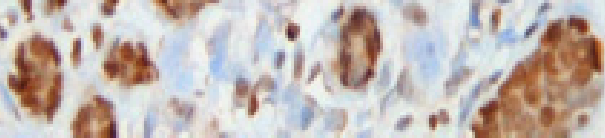

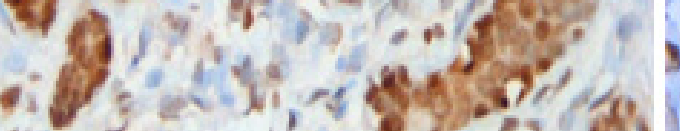

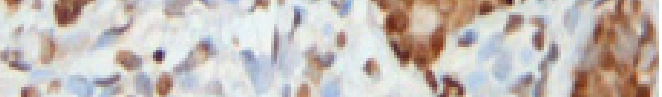

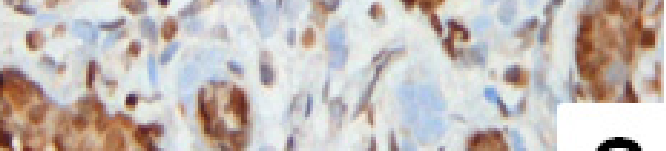

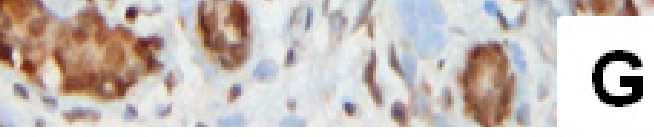

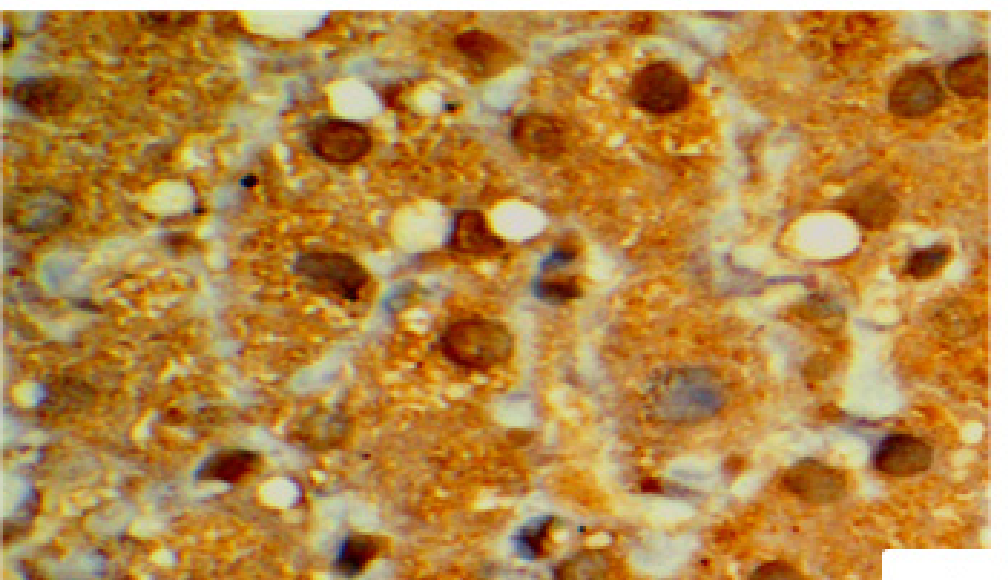




\section{Figure $3 \mathrm{~A}$}

Oncogenic Pathway Tumor Suppressor Pathway

\section{Wnt}

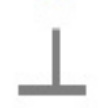

$$
\text { APC }
$$

Smads

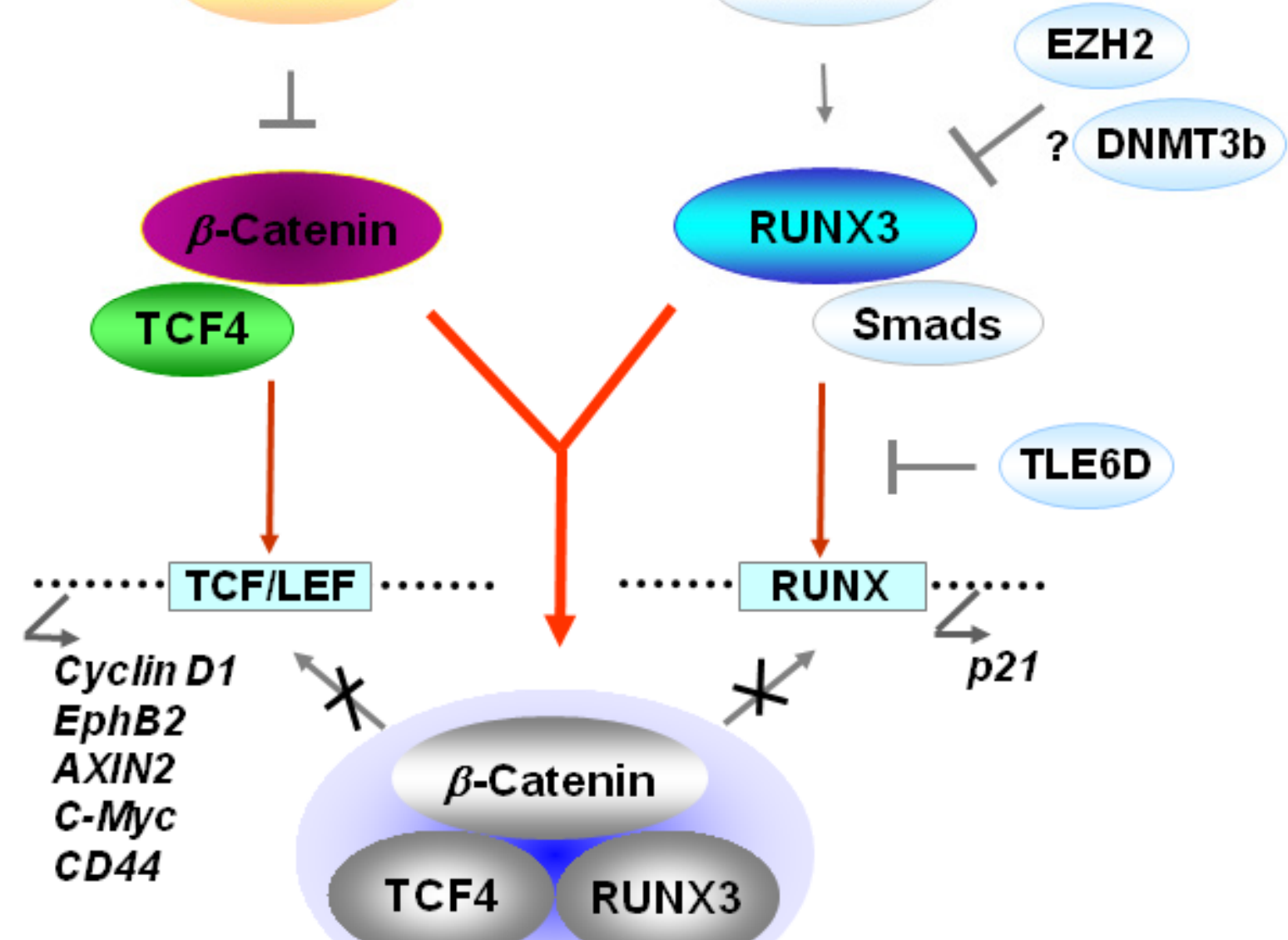




\section{Figure 3B}

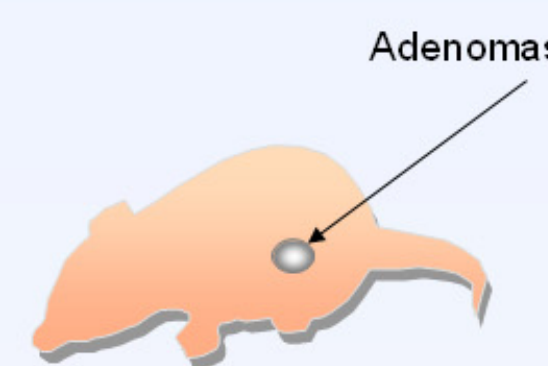

Runx $3^{+/-}$

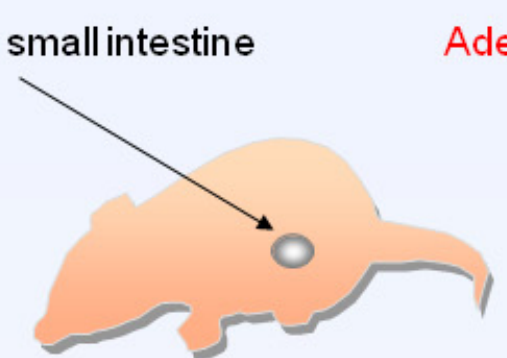

Apc $^{\mathrm{Min} /+}$

Adenocarcinomas in small intestine

Adenomas in large intestine

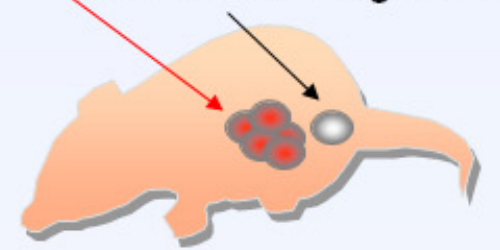

$\operatorname{Apc}^{\mathrm{Min} /+}$

Run $\times 3^{+/-}$

\section{LOH of Apc}

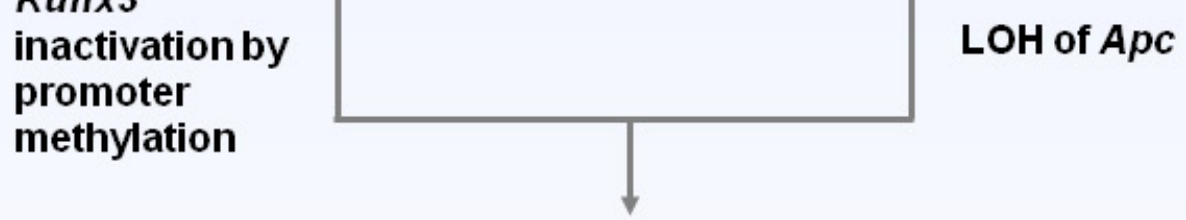

Adenomatouspolyps

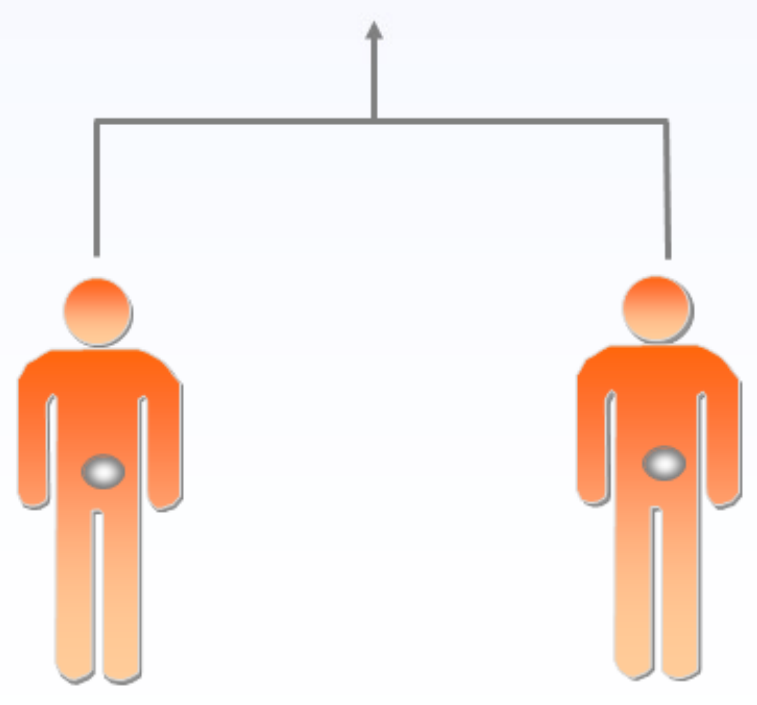

Normal $\beta$-catenin expression

$$
\text { and }
$$

or

Reduced RUNX3

expression

Nuclear/cytoplasmic $\beta$-catenin

$$
\text { and }
$$

Preserved RUNX3 expression

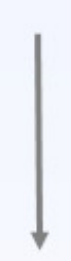

Adenocarcinomas

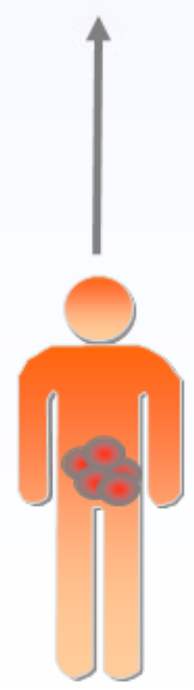

Nuclear/cytoplasmic $\beta$-catenin

Reduced RUNX3

expression 
Figure 4
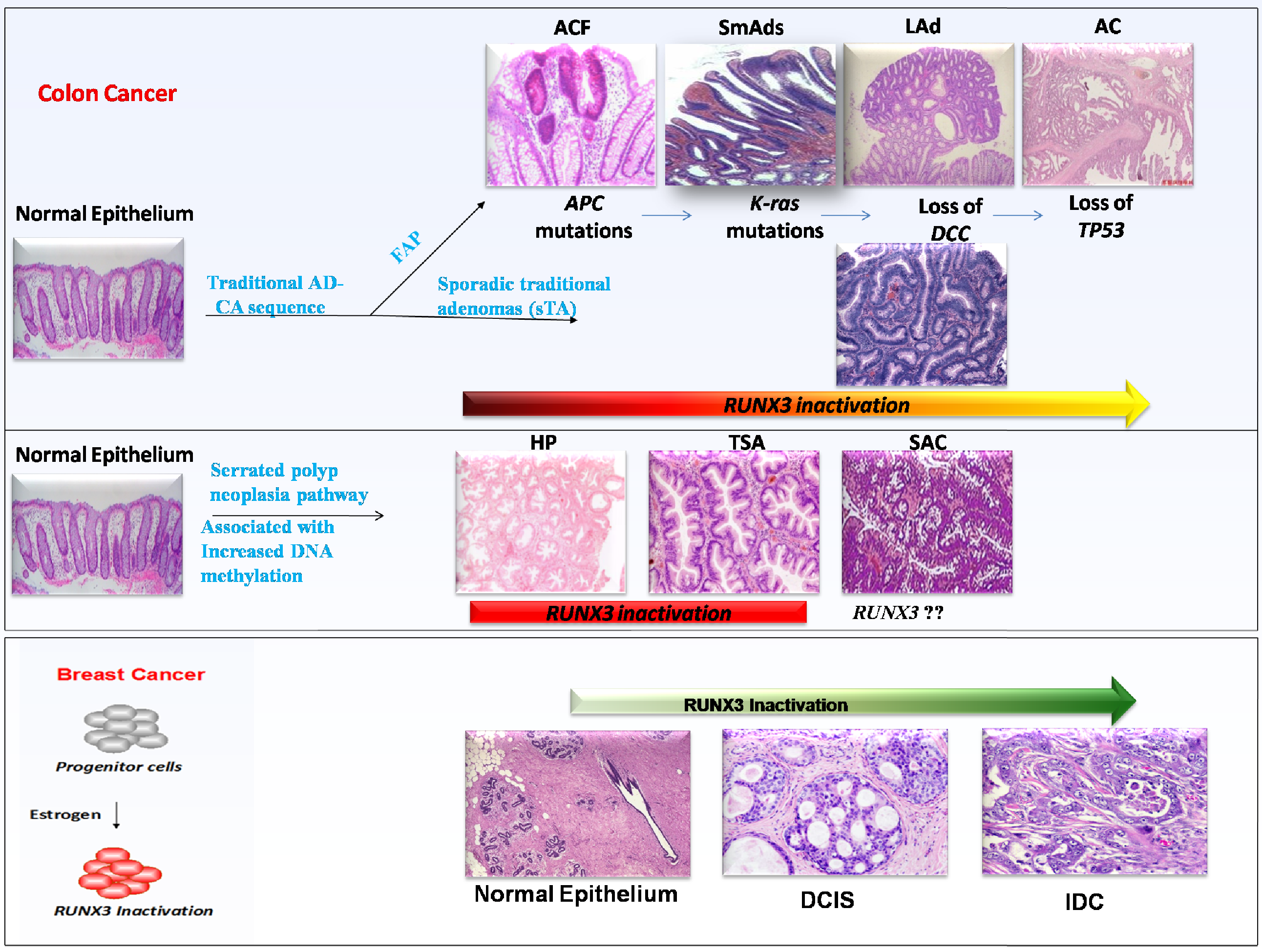